\title{
Fertility Decline in Pakistan 1980-2006
}

A Case Study

The World Bank

May 2010

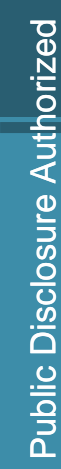

更 



\section{Fertility Decline in Pakistan 1980-2006 A Case Study}

May 2010 



\section{Contents}

Acknowledgments $\quad$ vi

Abbreviations vii

Executive Summary viii

$\begin{array}{ll}\text { Introduction } & 1\end{array}$

Political, Economic, and Social Progress Has Been Uneven 2

Fertility Transition and Current Fertility Status - Good but

Inconsistent Progress $\quad 4$

Four Proximate Determinants of Fertility in Pakistan - Differing

$\begin{array}{ll}\text { Effects on Fertility } & 6\end{array}$

Marriage and Sexual Union $\quad 6$

$\begin{array}{ll}\text { Use of Contraceptives } & 7\end{array}$

Induced Abortions $\quad 10$

Duration of Breastfeeding 11

Socio-Economic and Cultural Factors Influencing Fertility in Pakistan $\quad 12$

Child Mortality and Desired Family Size and Composition 12

$\begin{array}{ll}\text { Female Education } & 13\end{array}$

Women's Labor for Participation and Autonomy 15

Religion and Religious Leadership $\quad 16$

$\begin{array}{ll}\text { Role of Men and Spousal Communication } & 16\end{array}$

Government Population Policy and the Family Planning Service Provision $\begin{array}{ll}\text { An Early but Slow Start } & 18\end{array}$

Institutional Structure of the Family Planning Service Provision System 19

The Government Sector Service Delivery System for Family Planning 20

Role of the Private Sector and Nongovernmental Organizations 20

$\begin{array}{ll}\text { Status of the Family Planning Services } & 21\end{array}$

Government Financing of Population Programs 22 
Pakistan's Innovative Family Planning Programs

Innovations in Government Family Planning Programs 24

Innovations in NGO and Private Sector Programs Supported by Donors 25

Implications $\quad 29$

Annexes

Annex 1. Evaluation of the Lady Health Worker Program 30

Annex 2. Country-at-a-Glance: Pakistan 32

$\begin{array}{ll}\text { References } & 34\end{array}$

$\begin{array}{ll}\text { Endnotes } & 39\end{array}$

Figures

Figure 1. Map of Pakistan $\quad \mathrm{x}$

Figure 2. Total Fertility Rate in Pakistan, 1984-2000 5

Figure 3. Total Fertility Rate and Contraceptive Prevalence Rate in Pakistan, 1984-2005 8

Figure 4. Use of Modern Contraceptive Methods in Pakistan, 1990-91 and 2006-07

Figure 5. Infant Mortality Rate in South Asian Countries, 1980-2005 (per 1,000 Live Births)

Figure 6. Government Spending (Federal and Provincial) on Population and Health, 1987-2006 (Millions of Rupees)

\section{Tables}

Table 1. Socioeconomic Indicators in South Asian Countries, Circa 2005

Table 2. Progress Toward Health-Related Millennium Development Goal Targets in Pakistan

Table 3. Changes in Singulate Mean Age at Marriage in Pakistan, Selected Years, 1951-2003

Table 4. Contraceptive Methods Used by Currently Married Women Ages 15-49 by Background Characteristics

Table 5. Literacy Rates in Pakistan by Gender, Locale, and Province (Ages 10 and Older), 1981-2007 
Table 6. Government Expenditure on Population and Health and Average Annual Growth, 1990/91-2005/06 (percent)

Table 7. Trend in Total Fertility Rate and Contraceptive Prevalence Rate During 1990s

\section{Boxes}

Box 1. Role of International Donors

Box 2. World Bank Assistance to the Population Sector in Pakistan 


\section{Acknowledgments}

$\mathrm{T}$ his report was prepared by Naoko Ohno of the Health, Nutrition and Population unit of the South Asia region at the World Bank (SASHN), Sadia Chowdhury of the Health, Nutrition, and Population unit of the Human Development Network (HDNHE), Inaam Haq (SASHN), and Mehtab S Karim, previously at Aga Khan University, Karachi and presently at School of Public Policy, George Mason University.

The Population Council, Pakistan is gratefully acknowledged for providing pertinent background articles. The authors are grateful to the World Bank Library Research Services for assisting with the literature search. Mukesh Chawla, Sector Manager (HDNHE), and Julian Schweitzer, Sector Director (HDNHE), provided overall guidance and support. Thanks to Victoriano Arias (HDNHE) for providing administrative support.

This case study was part of a larger World Bank Economic and Sector Work entitled Addressing the Neglected MDG: World Bank Review of Population and High Fertility with an external advisory group comprising: Stan Bernstein (United Nations Population Fund), John Bongaarts (Population Council), John Casterline (Ohio State University), Barbara Crane (IPAS), Adrienne Germain (International Women's Health Coalition), Jean Pierre Guengant (L'Institut de recherché pour le développement), Jose Guzman (United Nations Population Fund), Karen Hardee (Population
Action International), Daniel Kraushaar (Bill and Melinda Gates Foundation), Gilda Sedgh (Guttmacher Institute), Amy Tsui (Johns Hopkins University, Bloomberg School of Public Health), and Wasim Zaman (International Council on Management of Population Programmes). The World Bank advisory group comprised: Martha Ainsworth (IEGWB), Peter Berman (HDNHE), Eduard Bos (HDNHE), Rodolfo Bulatao (HDNHE), Hugo Diaz Etchevere (HDNVP), Rama Lakshminarayanan (HDNHE), John May (AFTHE), Elizabeth Lule (AFTQK), and Thomas Merrick (WBIHS).

Bruce Ross-Larson, Communications Development Incorporated, edited the draft report and Samuel Mills (HDNHE) reviewed the final draft. The authors would like to thank the government of the Netherlands, which provided financial support through the World BankNetherlands Partnership Program (BNPP).

Correspondence Details:

$\rightarrow$ Sadia Chowdhury (HDNHE), World Bank, Mail Stop G7-701, 1818 H Street N.W., Washington, DC 20433, USA, Tel: 202-458-1984, email: schowdhury3@ worldbank.org

$\rightarrow$ This report is available on the following website: http://www.worldbank.org/hnppublications. 


\section{Abbreviations}

\begin{tabular}{|c|c|c|c|}
\hline \multirow[t]{3}{*}{ AFTHE } & Health, Nutrition, and & IUD & Intrauterine device \\
\hline & Population unit of the Africa & KfW & German development bank \\
\hline & region & KSM & Key Social Marketing \\
\hline \multirow[t]{2}{*}{ AFTQK } & Africa Operational Quality and & LHWP & Lady Health Worker Program \\
\hline & Knowledge Services & MDG & Millennium Development Goal \\
\hline GNI & Gross national income & NWFP & North West Frontier Province \\
\hline \multirow[t]{2}{*}{ GSMP } & Greenstar Social Marketing & PAVHNA & Pakistan Voluntary Health and \\
\hline & Pakistan & & Nutrition Association \\
\hline \multirow[t]{3}{*}{ HDNHE } & Human Development & SAP & Social Action Program \\
\hline & Network, Health,Nutrition, & SAPP & Social Action Program Project \\
\hline & and Population unit & SMP & Social Marketing Pakistan \\
\hline \multirow[t]{3}{*}{ HDNVP } & Office of the Senior Vice & VBFPW & Village-Based Family Planning \\
\hline & President and Head of Human & & Worker scheme \\
\hline & Development Network & WBIHS & World Bank Institute Health \\
\hline \multirow[t]{2}{*}{ IEGWB } & Independent Evaluation & & Systems \\
\hline & Group, World Ba & & \\
\hline
\end{tabular}




\section{Executive Summary}

P akistan is the world's sixth most populous country and has the second largest Muslim population after Indonesia. Since independence in 1947, Pakistan's turbulent political situation has frequently disrupted government development policies. Health status has improved since 1990, but the pace of improvement has been slow and performance lags behind other South Asian countries. Large gender disparities persist in education and health status, as well as in access to employment, assets, and justice.

Unlike in the other four case study countries (Algeria, Botswana, Iran, and Nicaragua), the history of fertility reduction in Pakistan has not been a story of unbroken successes but rather one of incomplete responses and shortcomings mingled with successes that offer lessons for other high-fertility countries. The total fertility rate in Pakistan stood at over an estimated 6.5 from the 1960s to the late 1980 s, when the fertility rate started to decline rapidly until 2000, when the decline seems to have stalled. Estimates of the current total fertility rate vary from 3.8 to 4.1 , roughly a 40 percent decline since the 1980s. Contraceptive prevalence also rose, from 12 percent in 1990 to 30 percent in 2006, but since then, has remained stagnant.

Several factors appear to have contributed to the decline in fertility in Pakistan. Among the proximate determinants are the proportion of women married (later age at marriage) and contraceptive use, with induced abortions perhaps also contributing. Key sociocultural contributors include smaller desired family size, greater female education and labor force participation, and better spousal communication, with obstacles to fertility decline being opposition to family planning by some religious leaders, husbands, and their mothers; women's low social status; and cultural prohibitions, such as, on women's travel alone outside the home.

Government and private sector family planning programs also contributed to the decline. Two innovative population programs begun in the 1990s are especially noteworthy. Large-scale community-based programs (the Village-Based Family Planning Worker scheme and the Lady Health Worker Program) brought family planning services to women's doorsteps as it became clear that geographic and socio-cultural constraints on women were resulting in underuse of services provided in fixed facilities. And private sector involvement in family planning began in the 1980s with the Greenstar Network of social marketing of contraceptives, which now provides 30 percent of modern contraceptives used in Pakistan, making it the second largest family planning service provider after the government.

During the 1990s, family planning services improved and contraceptive prevalence rates more than doubled, likely contributing 
to the decline in the total fertility rate over that period. However, the programs have considerable room for improvement, and Pakistan has made little progress in reducing socio-cultural constraints to family planning related to religion, gender, and locale, which likely have reduced the effectiveness of population programs. The government needs to address these underlying constraints and program shortcomings to meet the high level of unmet demand for contraceptives if it is to accelerate and sustain fertility reduction. 
Figure 1 1 Map of Pakistan

$19 R 033460$

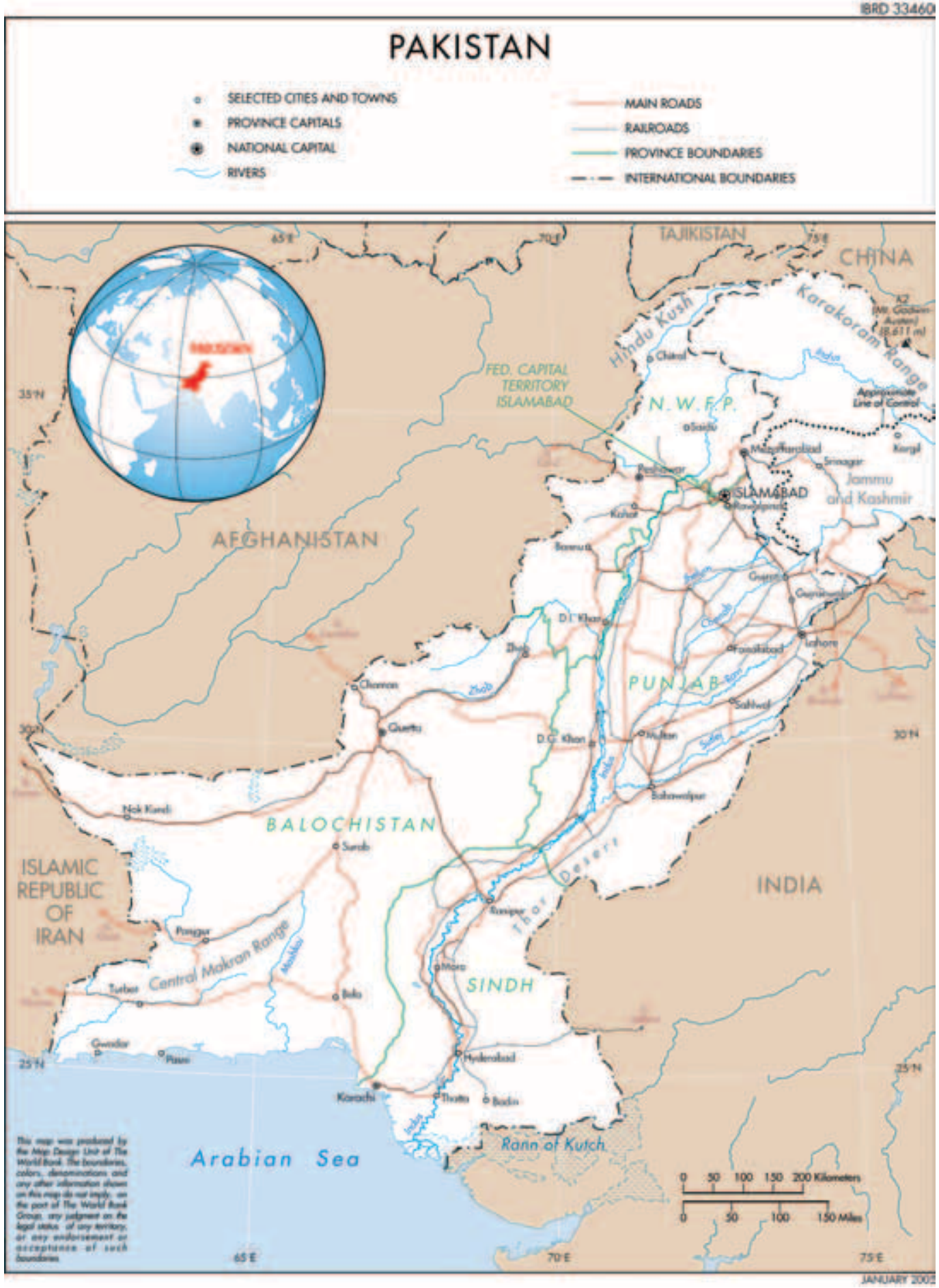

Source: World Bank Map Design Unit.

Fertility Decline in Pakistan, 1980-2006 | A Case Study 


\section{Introduction}

akistan was selected as a case study because of its estimated 40 percent decline in fertility between 1980 and 2006. Pakistan's high fertility rate began to decline gradually after the late 1980s and has continued to fall since then, though progress has been uneven and there have been signs of a slowdown in recent years. Unlike the other four case study countries (Algeria, Botswana, Iran, and Nicaragua), the history of fertility reduction in Pakistan has not been an overwhelming success story but rather a story of challenges, partial responses, and shortcomings that offer abundant lessons for other high-fertility countries as well as planners in Pakistan. 


\section{Political, Economic, and Social Progress Has Been Uneven}

$\mathrm{P}$ akistan is the world's sixth most populous country (its 2009 population is estimated as 171 million by Ministry of Population Welfare, Government of Pakistan, and 181 million by the United Nations Population, Division), with a gross national income (GNI) per capita of US\$800 in $2006 .{ }^{1}$ Some 97 percent of the population is Muslim. Pakistan is a federation of four provincesBalochistan (the largest, but with just 5 percent of the population), North West Frontier Province (NWFP, with 13 percent), Punjab (with 56 percent), and Sindh (23 percent) and four territories-Islamabad Capital Territory, federally administrated tribal areas, Azad Jammu and Kashmir, and federally administered Northern Areas. Azad Jammu and Kashmir is semiautonomous but indirectly administered by the government of Pakistan as separate political entity while, federally administered Northern Areas, has recently been given the status of a province.

Since independence in 1947, Pakistan has had a turbulent political history, with repeated coups impeding the maturation of political institutions and democracy, interrupting development efforts, and delaying social development and the emergence of a market economy.

After rapid economic growth in the 1970 s to 1980 s that sharply reduced poverty, impru- dent policies and declining international support because of Pakistan's nuclear program led to an economic slowdown in the 1990s. Average annual growth stagnated at around 4 percent over the 1990 s, contributing to a rapid increase in poverty. Falling tax revenues limited the government's ability to provide critical social services. Fiscal deficits were high throughout most of the 1990s, adding to rising public sector indebtedness. Poverty gaps across regions and provinces persisted or widened. During the first five years of 2000, wideranging economic reforms and a shifting of the international political environment resulted in a stronger economic outlook and accelerated growth, especially in manufacturing and financial services. However, the current global economic crisis, with rising food and oil prices, has slowed economic growth and threatens to reverse the declining trend in poverty.

Human development has long been neglected in Pakistan. While health status has improved since the 1990s, the rate of improvement has been slow, and performance lags behind South Asian countries (table 1). Gender disparities persist in education and health outcomes as well as in employment, assets, and justice because of unequal access to opportunities and services.

As a result, Pakistan has made only slow progress toward the Millennium Development 
Table 1 Socioeconomic Indicators in South Asian Countries, Circa 2005

\begin{tabular}{lccccc}
\hline Country & $\begin{array}{c}\text { GNI per capita } \\
\text { (US\$) }\end{array}$ & $\begin{array}{c}\text { Life expectancy } \\
\text { at birth, female } \\
\text { (years) }\end{array}$ & $\begin{array}{c}\text { Under-five } \\
\text { mortality rate } \\
\text { (per 1,000 live } \\
\text { births) }\end{array}$ & $\begin{array}{c}\text { Births attended } \\
\text { by skilled staff } \\
\text { (percentage of } \\
\text { births) }\end{array}$ & $\begin{array}{c}\text { Total fertility } \\
\text { rate } \\
\text { (per woman) }\end{array}$ \\
\hline Pakistan & 860 & 66 & 90 & 39 & 4.0 \\
\hline Bangladesh & 470 & 65 & 60 & 18 & 2.9 \\
\hline India & 950 & 66 & 72 & 47 & 2.7 \\
Nepal & 350 & 64 & 55 & 19 & 3.1 \\
\hline Sri Lanka & 1540 & 76 & 20 & 98 & 1.9 \\
\hline
\end{tabular}

Source: World Bank 2006, 2007.

Goal targets, although there has been steady improvement in recent years. While under-five and infant mortality rates have fallen, Pakistan, like most South Asian countries, made little progress in reversing child malnutrition in the 1990s. Improvement in the maternal mortality ratio has also been slow. However, health service indicators, such as immuniza- tion coverage and births attended by skilled staff, have improved considerably. The government has committed to achieving the Millennium Development Goal targets, but to accelerate progress to reach the targets, substantial additional resources and effort will be required.

\section{Table 2 Progress Toward Health-Related Millennium Development Goal Targets in Pakistan}

\begin{tabular}{lcc}
\hline & 1990 or & 2005 or \\
Target and indicator & 1991 & 2006 \\
\hline Reduce by two-thirds, between 1990 and 2015, the under-five mortality rate & 130 & 97 \\
\hline Under-five mortality rate (per 1,000 live births) & 100 & 78 \\
\hline Infant mortality rate & 50 & 80 \\
\hline Percent of children 12-23 months immunized against measles & 340 & 320 \\
\hline Reduce by three-quarters, between 1990 and 2015, the maternal mortality ratio & 19 & 31 \\
\hline Maternal mortality ratio (per 100,000 live births) & 50 \\
\hline
\end{tabular}

Source: United Nations Millennium Development Goals Indicators database (http://mdgs.un.org/unsd/mdg/Data.aspx) March 25, 2009. 


\section{Fertility Transition and Current Fertility Status - Good but Inconsistent Progress}

$\mathrm{n}$ the late $1980 \mathrm{~s}$, the fertility rate began to decline in Pakistan after a long period of sustained high fertility, dropping by 40 percent over the past two decades. The history of population policies and outcomes in Pakistan is not one of unqualified success, however, but rather a series of challenges, advances, and setbacks. There are abundant lessons for high-fertility countries in Pakistan's experience. This case study highlights likely factors that have influenced fertility change in Pakistan.

The total fertility rate was more than 6 children per woman until the 1980 s. $^{2}$ Survey estimates show the rate falling below 6 children for the first time during the 1990s and declining consistently until the 2000s. ${ }^{3}$ The latest Pakistan Demographic and Health Survey, for 2006-07, shows a total fertility rate of 4.1 children in 2004-06, and the rate appears to have stalled more recently. A decline of 1.8 children per woman per decade, based on the estimates from the Pakistan Demographic Survey, is remarkably fast compared with the decline of 1.5 for East and Southeast Asian countries. ${ }^{4}$

Surveys provide varying estimates of the fertility rate. ${ }^{5}$ A 2003 analysis of survey data suggests that surveys based on birth histories, such as the Pakistan Demographic and Health Survey 1990-91 and the 1997 Pakistan Fertility Family Planning Survey, underestimated the total fertility rate. ${ }^{6}$ Many demographers disputed the fertility rate of 5.5 estimated by the Pakistan Demographic and Health Survey 1990-91, especially in light of the low 12 percent contraceptive prevalence rate at the time.

Demographers tend to agree on the late 1980 s as the onset of the fertility decline. Some argue that it began between 1987 and 1988 and lasted until at least 2000, based on Pakistan Demographic Survey data. ${ }^{7}$ This position is supported by estimates from the 1998 Census and the 2000-01 Pakistan Reproductive Health and Family Planning Survey. Another study argued that the onset was probably in the early 1990s or in the late 1980 s, noting that data from the 1990 s exhibit a clear decline in fertility levels and that estimates imply a modest decline of around one birth per woman between 1980s and the 1990s. ${ }^{8}$ The Pakistan Demographic Survey data show a decline after the late 1980 s (figure 2). 
Figure 2 Total Fertility Rate in Pakistan, 1984-2000

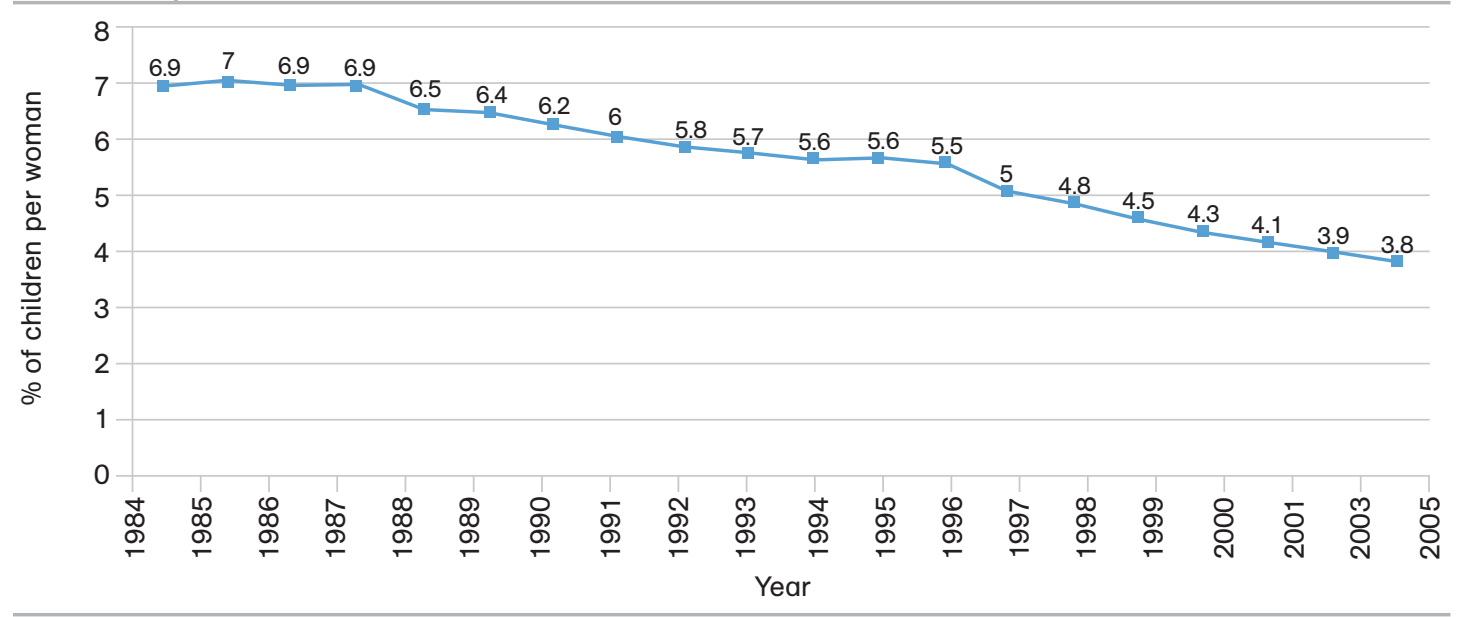

Source: For 1984-2000, Pakistan Demographic Survey from Feeney and Alam 2003a; for 2001, 2003, and 2005, Pakistan Demographic Survey. 


\section{Four Proximate Determinants of Fertility in Pakistan - Differing Effects on Fertility}

T

his section reviews the literature on four proximate determinants of fertility in Pakistan: proportion of women married; contraceptive prevalence rate; prevalence of induced abortion; and duration of postpartum infecundability as measured by length of exclusive breastfeeding. ${ }^{9}$ According to two studies in 1994, of these four factors, the contraceptive prevalence rate had the weakest effect on fertility reduction and postpartum infecundability the strongest. ${ }^{10}$ The effect of induced abortion was not fully considered, however, because of a dearth of evidence on abortions, which are illegal in Pakistan. Underestimating the effect of abortions likely distorted the analysis of Pakistan's fertility reduction, as the prevalence of induced abortion appears to be notably high (see the section on induced abortion). Examination of other recent evidence suggests that age at marriage, contraceptive prevalence, and induced abortion contributed most to fertility reduction, whereas postpartum infecundability was the least influential in case of Pakistan.

\section{Marriage and Sexual Union}

With contraceptive prevalence at a persistently low rate in Pakistan, studies suggest that the rise in the age at marriage for women and proportion of women never married at age 15-19 likely played a key role in fertility decline. ${ }^{11}$ One research described "dramatic" changes in marriage patterns. ${ }^{12}$ The singulate mean age at marriage ${ }^{13}$ for women rose from 20.2 in 1981 to 22.3 in 2003, and the proportion of young women ages 15-19 who were never married rose from 71 percent to 87 percent (table 3). However, the data suggest that the largest rise in the female singulate mean age at marriage (a 3-year increase) and percentage of women never married ages 15-19 (more than 40 percent increase) occurred between 1961 and 1972, without triggering any notable decline in the total fertility rate in the time period.

The median age at first birth for women ages 25-49 also shows a gradual rise, from 20.3 in $1990-91$ to 21.8 years in $2006-07 .{ }^{14}$ While the overall increase is small, the largest increase occurred among women in the most fertile age group of 25-29 years (from age 21.0 in 1990-91 to age 22.7 in 2006-07). Women's education and family's wealth levels are linked to the onset of childbearing; women in higher education or higher wealth groups delay childbearing for about 2 years.

The median birth interval in Pakistan is 28.8 months, which shows a decline of 


\begin{tabular}{|c|c|c|c|}
\hline \multirow[b]{3}{*}{ Year } & \multirow{2}{*}{\multicolumn{2}{|c|}{ Singulate mean age at marriage (years) ${ }^{a}$}} & \multirow{3}{*}{$\begin{array}{c}\text { Percentage of women } \\
\text { never married, ages } 15-19\end{array}$} \\
\hline & & & \\
\hline & Male & Female & \\
\hline 1951 & 22.3 & 16.9 & 27.1 \\
\hline 1961 & 23.3 & 16.7 & 25.4 \\
\hline 1972 & 25.7 & 19.7 & 65.6 \\
\hline 1981 & 25.1 & 20.2 & 70.6 \\
\hline 1998 & 25.8 & 21.7 & 79.4 \\
\hline 2003 & 26.4 & 22.3 & 86.6 \\
\hline
\end{tabular}

Source: Sathar 2007, based on data from Pakistan Demographic Survey 2003.

a. A measure comparing the age-specific proportions of women who have never been married with the age-specific proportions of those who have ever been married to calculate the mean age at which the transition between the two occurs. It is used to estimate mean age at marriage in countries where marriage records are absent or deficient.

0.3 month from $1990-91 . .^{15}$ It is considerably shorter than in other South Asian countries such as India (31 months), Nepal (34 months), Bangladesh (39 months), and Sri Lanka (52 months). ${ }^{16}$ The median birth interval is shorter if the previous child was a girl (28.0 months) than if it was a boy (29.6 months), implying a persistent preference for sons. Birth intervals are much shorter if the previous child died (21.9 months) than if it survived (29.6 months). Birth intervals are shortest for women ages 15-19 (20.9 months). Women with the highest education level have a slightly shorter interval (28.0 months) than uneducated women (28.7 months); there is little difference in the interval length for rural (28.9 months) and urban areas (28.7 months). In conclusion, birth intervals have changed little over time and therefore have likely not contributed directly to the fertility decline.

\section{Use of Contraceptives}

Higher contraceptive prevalence rates among women are an important contributor to the fertility rate decline. In Pakistan, when the total fertility rate began to decline in the early 1990s, the contraceptive prevalence rate, though low, was moving upward (figure 3). Some researchers have argued that the rising contraceptive prevalence rate among married couples was the main reason for the fertility rate decline in the 1990 s. $^{17}$

Several studies have examined the factors influencing the use of contraceptives in Pakistan. Knowledge of contraceptives among ever and currently married women is almost universal (96 percent), with knowledge greater for modern methods than for traditional methods. ${ }^{18}$ Yet contraceptive use has remained low. Further reducing the fertility rate in Pakistan requires understanding why the high level of knowledge about family planning does not lead to greater use of family planning.

Contraceptive prevalence rates among currently married women ages 15-49 hardly changed until 1990, when the rate began to rise. From a very low rate of 12 percent in 1990-91, contraceptive prevalence more than 


\section{Figure 3 Total Fertility Rate and Contraceptive Prevalence Rate in Pakistan, 1984-2005}

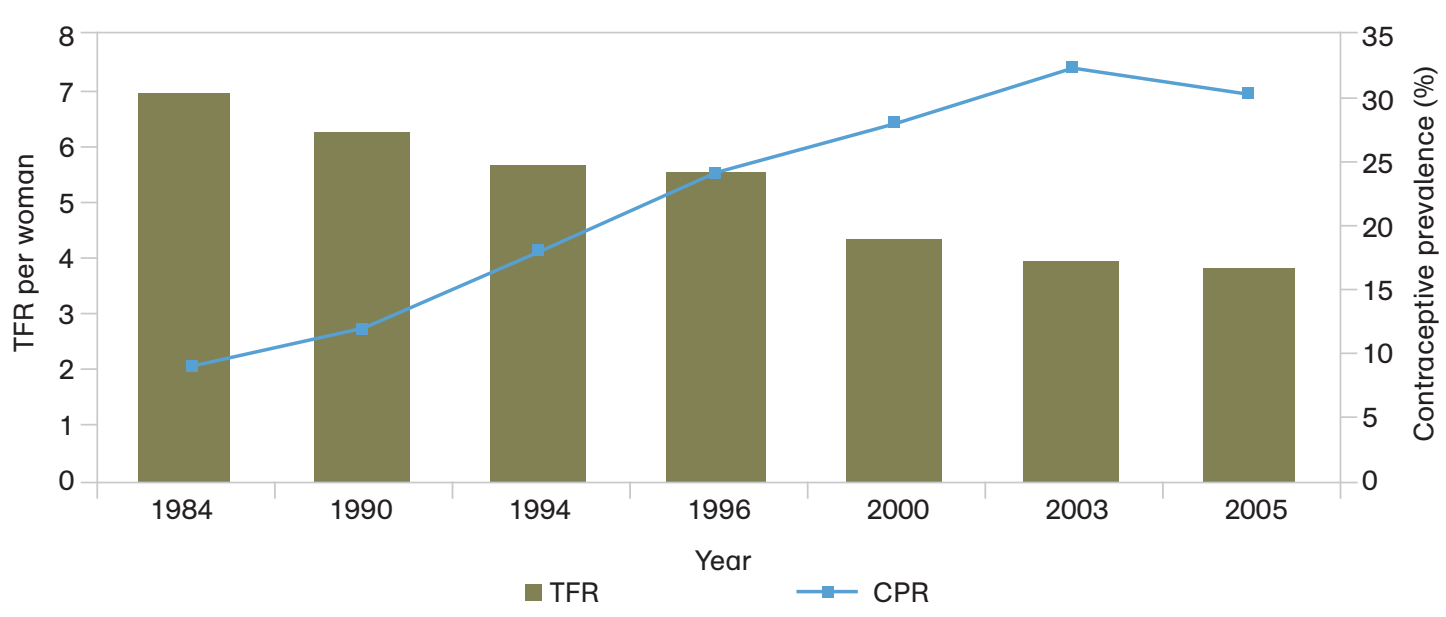

Note: Total fertility rate is calculated based on interviews with women ages 15-49; the contraceptive prevalence rate is based on currently married women in the same age group.

Source: Total fertility rate data from Feeney and Alam 2003a, based on data from Pakistan Demographic Surveys, and Pakistan Demographic Survey 2003 and 2005; contraceptive prevalence rate data from Pakistan Demographic and Health Survey 2006-07 (National Institute of Population Studies and Macro International Inc. 2008).

doubled by $2006-07$ to 30 percent. ${ }^{19}$ There is some indication of a plateau in recent years. The most widely used method is female sterilization, followed by condoms, withdrawal, and the rhythm method. As expected, contraceptive prevalence increases with a woman's education level, wealth, and urban residence (table 4). Among currently married women, contraceptive prevalence is highest in Punjab (33 percent) and lowest in Balochistan (14 percent). More than half of currently married women ages 15-49 either do not want another child in the future or are sterilized. Demand for limiting childbearing also has substantially risen from 40 percent in 1990-91 to 52 percent in 2006-07. ${ }^{20}$ Yet the rate of increase in contraceptive use has remained slow.

About three-quarters of current users employ modern methods, a proportion unchanged since 1990. Among modern methods, the most common is female sterilization, followed by condoms, intrauterine device (IUD)/injectables, and oral contraceptives, especially among women in rural areas, those in the poorest 20 percent of the population, and those with no education. ${ }^{21}$ For women in urban areas, in the richest 20 percent, or with a higher education, condoms are the most commonly used method. By province, the most commonly used modern methods are female sterilization and condoms in Punjab and Sindh, condoms and withdrawal in NWFP, and oral contraceptives and female sterilization in Balochistan. Women opt for sterilization only after they have had many children (often five or more), so female sterilization may not be a suitable option for lowering the fertility rate.

Use of contraceptives increased in both rural and urban areas from 1990-91 to 2006-07 (figure 4). ${ }^{22}$ In urban areas, there was 
Table 4 Contraceptive Methods Used by Currently Married Women Ages 15-49 by Background Characteristics

\begin{tabular}{lcc}
\hline Characteristic & Any method & Any modern method \\
\hline Residence & & \\
\hline Urban & 41.1 & 29.9 \\
\hline Rural & 23.9 & 17.7 \\
\hline Province & & \\
\hline Balochistan & 14.4 & 13.4 \\
\hline NWFP & 24.9 & 18.7 \\
\hline Punjab & 33.2 & 23.1 \\
\hline Sindh & 26.7 & 22.0 \\
\hline Education & & \\
\hline None & 25.3 & 18.9 \\
\hline Higher & 42.6 & 31.4 \\
\hline Wealth & & \\
\hline Poorest 20 percent & 15.6 & 12.4 \\
\hline Richest 20 percent & 43.4 & 31.6 \\
\hline Total & 29.6 & 21.7 \\
\hline
\end{tabular}

Source: Pakistan Demographic and Health Survey 2006-07 (National Institute of Population Studies and Macro International Inc. 2008).

Figure 4 | Use of Modern Contraceptive Methods in Pakistan, 1990-91 and 2006-07

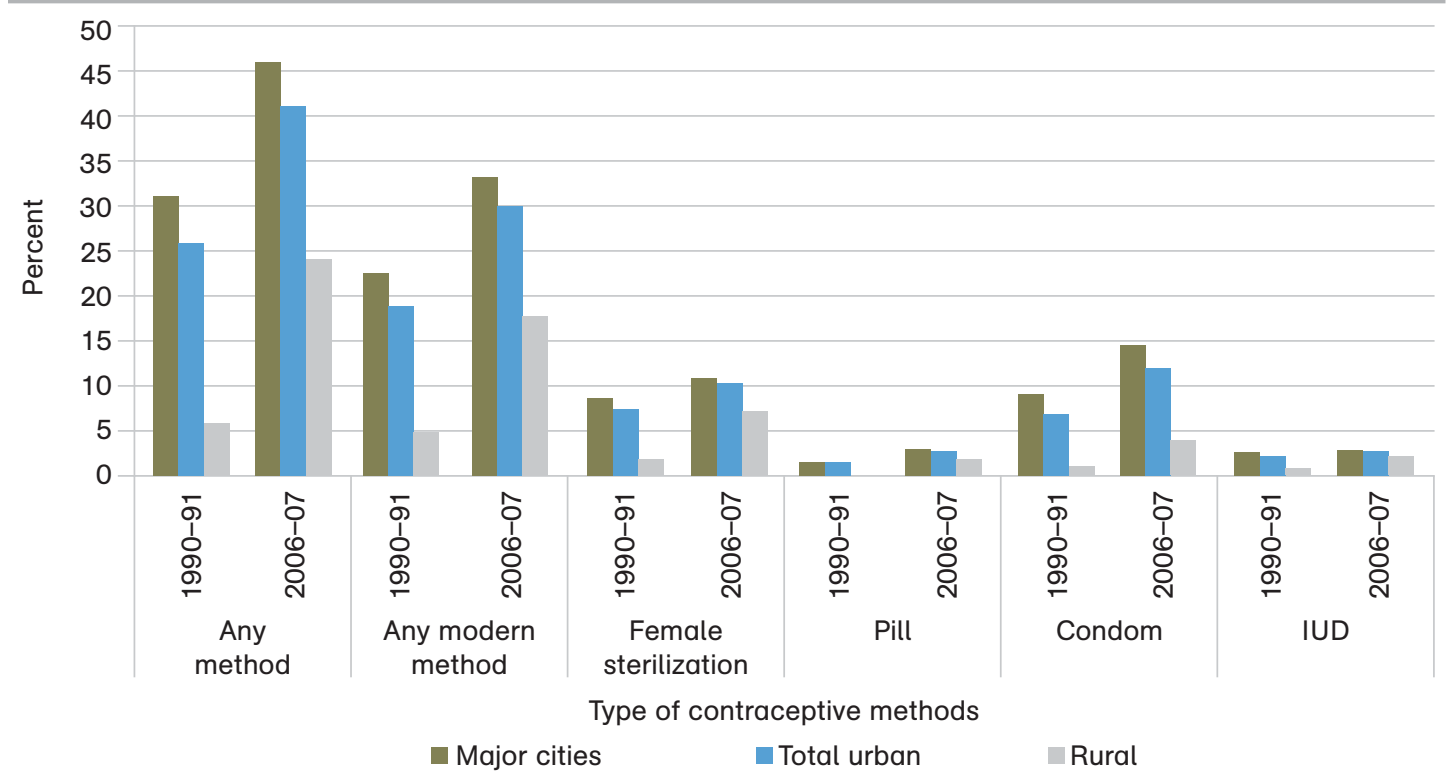

Source: Pakistan Demographic and Health Survey 2006-07 (National Institute of Population Studies and Macro International Inc. 2008). 
a slight increase in female sterilization, a large increase in oral contraceptive and condom use, and no major change in the use of the IUD. The increase in oral contraceptive and condom use could reflect the impact of social marketing projects in urban areas (see section on innovations in family planning programs). In rural areas, there was a large increase in acceptance of modern methods, especially female sterilization, oral contraceptive, and condom use.

Despite the rise in contraceptive use since the 1990s, Pakistan faces a high level of unmet need-25 percent among currently married women. ${ }^{23}$ That is comparable to rates in SubSahara African countries and, in Asia, to rates in Nepal (24.6 percent) and Cambodia (25.1 percent). ${ }^{24}$ In India, the unmet need is lower, at 13 percent. ${ }^{25}$ Use of contraceptives by women is affected by such factors as husband's approval, religious belief, fear of side effects, lack of access to services, poor communication between spouses, mother-in-law's influence, and cost (see section on socioeconomic and cultural factors), ${ }^{26}$ all factors that could be addressed with the proper strategies.

\section{Induced Abortions}

Termination of pregnancy is illegal in Pakistan, except to save the mother's life. However, considering the low contraceptive prevalence rate, the high unmet contraceptive need, and the strong desire to limit childbearing, it can be assumed that many women in Pakistan are at risk of an unwanted pregnancy and induced abortion. Although it is difficult to get an accurate figure because induced abortions are illegal, 1.5 percent of ever-married women are estimated to have experienced induced abortions. ${ }^{27}$ The actual rate could be even higher, as the reported level of miscarriage is high at 8.1 percent, which might have included some induced abortions. Estimates in the published literature vary. One nationwide study, using the medium estimate of 35 percent of late term spontaneous abortions treated in a hospital estimates that 890,000 induced abortions are performed annually in Pakistan for a national annual induced abortion rate of 29 per 1,000 women ages $15-49$ (2.9 percent). ${ }^{28}$ Another study estimated the abortion rate at 4.1 percent from a sample of 1,214 women in low-income squatter settlements of Karachi. ${ }^{29}$ Unplanned and mistimed pregnancies due to ineffective use of contraceptives and high unmet need are the main reasons women reported choosing induced abortion.

The aforementioned nationwide study estimated an abortion ratio of 14 per 100 pregnancies, meaning that a surprisingly high one in seven pregnancies is terminated by induced abortion in Pakistan. ${ }^{30}$ This finding implies that induced abortions might have greatly influenced fertility levels. The study found a relationship between the level of contraceptive use and the level of abortions, with estimated abortion rates higher in provinces with lower contraceptive prevalence rates (NWFP and Balochistan). Though the study used the medium-level estimate, the rates may be underestimated because they are based on estimated post-abortion hospitalizations, and the survey did not include private sector facilities or public primary health care centers.

Poverty and already having the desired number of children are the most common reasons reported by women seeking abortions. In one study, 20 percent of respondents reported contraceptive failure (mostly tradi- 
tional methods) as the main reason. These findings suggest that women face difficulty obtaining reliable family planning methods and use abortion as a back-up method to terminate unintended pregnancies. ${ }^{31}$

One study in six tertiary hospitals in Karachi, Lahore, and Peshawar found that more than 90 percent of staff in the departments of obstetrics and gynecology had encountered abortion cases one month prior to the survey. ${ }^{32}$ More than half were due to unwanted pregnancy and a quarter to contraceptive failure. Most health care providers (87 percent) looked unfavorably on induced abortion, and their religious beliefs were significantly associated with the practices. Physicians believed that sharp curettage was more common, though vacuum aspiration is safer and less expensive. Contraceptive counseling services following abortion are often missing. Thus, patients seeking abortion-related services may receive insufficient or inappropriate treatment from health professionals. Often, women who decide not to go to government hospitals in order to avoid such treatment seek unsafe abortions from unskilled abortionists and traditional healers.

\section{Duration of Breastfeeding}

Breastfeeding likely has had little if any impact on fertility reduction in Pakistan. Following childbirth, the median duration of amenorrhea is 3.9 months, abstinence 2.1 months, and women's insusceptibility an estimated 4.8 months. ${ }^{33}$ The median duration of exclusive breastfeeding is only 3.2 months, and less than a quarter of newborns below age six months are exclusively breastfed. Postpartum abstinence extends to 40 days after birth according to the Muslim tradition. Thus the major determinant of the length of insusceptibility is likely amenorrhea. Amenorrhea is longer among women in rural areas (5.1 months) than urban areas (4.1 months), among poor women (4.4 months) than rich (2.8 months), and among women with no education (4.4 months) than women with a secondary education (2.4 months). 


\section{Socio-Economic and Cultural Factors Influencing Fertility in Pakistan}

M

any socioeconomic and cultural factors influence fertility in Pakistan, particularly child mortality, female education, women's labor market participation, religion, and the influence of husbands and spousal communication.

\section{Child Mortality and Desired Family Size and Composition}

Pakistan's infant mortality rate and underfive mortality rate have gradually declined, but improvement has been slow compared with that in neighboring South Asian countries and threatens achievement of the Millennium Development Goal targets in child health. Bangladesh and Nepal, which had a much higher infant mortality rate than Pakistan in 1980, have made remarkable progress, lowering infant mortality rates to 40 percent of their 1980 levels (figure 5). India, whose infant mortality rate in 1980 was similar to Pakistan's, has also made steady progress, and its rate today is considerably lower than Pakistan's. While reduced child mortality is known to have an impact on declining fertility, it is unclear to what extent this slow change in child mortality has affected desired fertility in Pakistan.

Other data, though differing slightly from those in figure 4, also show a gradual decline in the infant mortality rate from 91 to 78 per 1,000 live births and in the underfive mortality rate from 117 to 94 per 1,000 live births. ${ }^{34}$ More than half the reported deaths in children under five occur during the neonatal period. Mother's education and wealth, birth intervals, and residence are highly correlated with child mortality. One study found that mother's education, breastfeeding, place of delivery, and prenatal care were the most important factors affecting child mortality risk. ${ }^{35}$

A desire to limit additional children is strongly associated with the number of a woman's living children, reaching 55 percent among women with three children and 88 percent among those with six or more. The desire to limit childbearing has been rising in Pakistan, from 40 percent of currently married women in 1990-91 to 52 percent in 2006-07. ${ }^{36}$ Women with higher education, in the wealthiest 20 percent, and living in urban areas have the lowest desire for additional children.

The mean ideal number of children is 4.1 for ever-married and currently married women, a number unchanged since $1990-91 .^{37}$ The mean ideal number of children is lowest in Punjab (3.8) and highest in NWFP (5.9). Many women have more children than they would prefer; 54 percent of women with six or more children have ex- 
Figure 5 Infant Mortality Rate in South Asian Countries, 1980-2005 (per 1,000 Live Births)

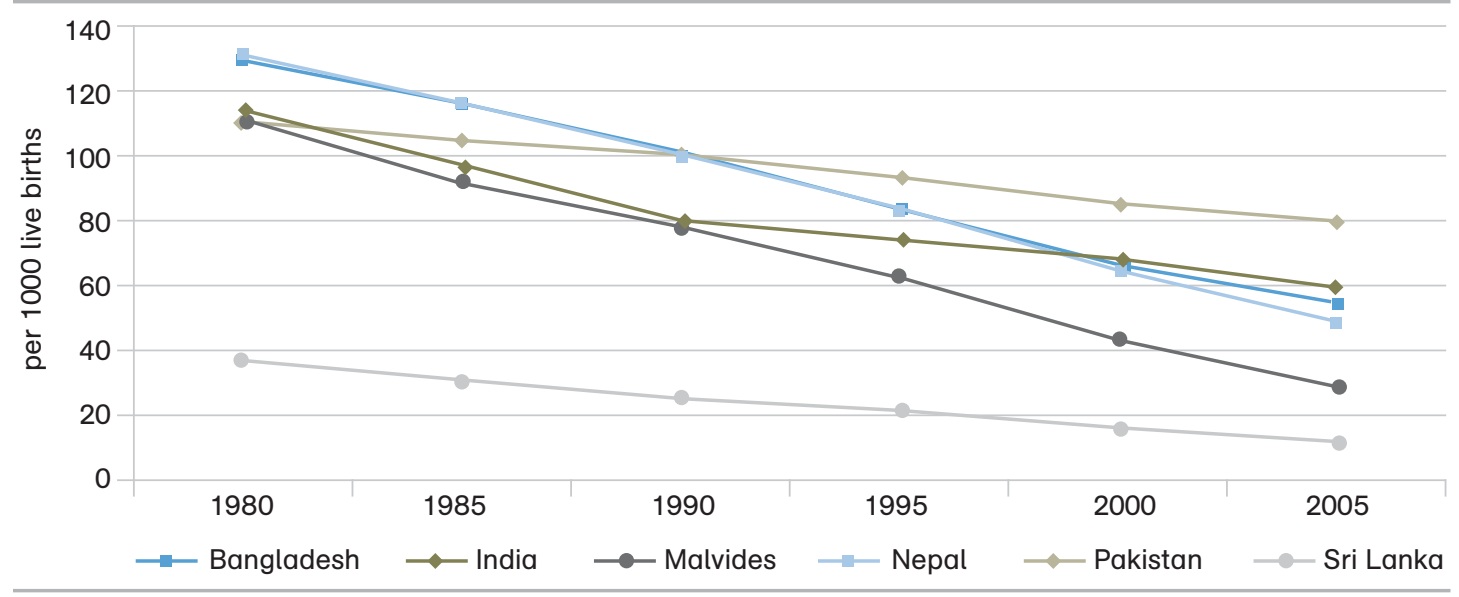

Source: World Bank, various years, World Development Indicators.

ceeded their ideal family size, as have 52 percent of those with five children.

Desired family size is closely associated with the desire for sons in Pakistan and other South Asian countries, where there is a strong preference for sons. ${ }^{38}$ In in-depth interviews in a study of low-income women in Punjab, women expressed a strong son preference, mostly for economic reasons, reflecting women's subordinate social status and the low economic value placed on women's work. ${ }^{39}$ In some rural areas, especially in Punjab, raising daughters is too costly because of the need for a dowry. Among Pakistani women with three children, 65 percent of those with three sons want no more children compared with only 14 percent of those with three daughters. A longitudinal study in an urban slum in Karachi found that the sex of surviving children, particularly the number of sons, is associated with unwanted pregnancies and influences subsequent reproductive behavior. ${ }^{40}$ The study reports a marked increase in contraceptive use among women with two or more surviving sons and one or more surviving daughters. Bearing sons is a way for women to increase their status.

Husbands and mothers-in-law also affect women's desire for family planning, with negative impacts on family size. Opposition to family planning by mothers-in-law stems from a desire for more grandchildren, especially sons, and the traditional belief that Islam forbids family planning. ${ }^{41}$ About half the women in an urban slum study reside with their mother-in-law, so that negative attitudes from both husband and mother-inlaw may be a formidable barrier to the use of contraceptives. ${ }^{42}$

\section{Female Education}

Female education, by increasing a woman's knowledge and ability to make independent decisions, is likely to contribute to lower fertility. ${ }^{43}$ Both proximate determinants of fertility, such as age at marriage and use of contraceptives, and socioeconomic and cultural factors, such as child mortality and 
spousal communication, are highly correlated with a woman's educational attainment.

Though long neglected, women's education has gradually been improving (table 5). The female literacy rate nearly tripled, from 16 percent in 1981 to 42 percent in 2006-07, and the rural-urban literacy gap shrank from about $1: 5$ to $1: 2$. The female literacy rate is highest in Punjab (46.4 percent) and lowest in Balochistan (23.3 percent). But the gap between rural Balochistan women (15.7 percent) and urban Punjab women (64.3 percent) is quite wide (1:4).

The rural-urban gap also exists for primary and secondary schooling. The primary school enrollment rate for girls is 45.5 percent, but 64.6 percent for urban girls and 39.3 percent for rural girls. Similarly, the secondary school enrollment rate is 27.1 percent, but 49.5 percent for urban girls and 17.3 percent for rural girls. ${ }^{44}$

While the proportion of women with a secondary or higher education has doubled among women of reproductive age, less than half of girls are enrolled in primary school, only a quarter of women have a primary education, and more than half of women have received no education. ${ }^{45}$

Expansion of female higher education has a significant impact on fertility by delaying marriage and birth of the first child. Pakistan needs to promote universal primary education first as a pathway to moving up to secondary and higher education for women. International evidence shows that female primary education also lowers the fertility rate, though the net effect is only a third that for secondary school. ${ }^{46}$ Among the constraints to female primary enrollment are distance from school, especially in rural areas (schools are overwhelmingly located in wealthier communities); school expenses, parents' reluctance to educate girls, and scarcity of female teachers. ${ }^{47}$

A study in rural communities in Punjab and NWFP found that the accessibility and quality of public primary schools within the community positively influenced the fertility transition in rural Pakistan. ${ }^{48}$ The study estimated that gender equity in primary school access in rural Pakistan could lead to a 14-15

\section{Table 5 Literacy Rates in Pakistan by Gender, Locale, and Province (Ages 10 and Older), 1981-2007}

\begin{tabular}{|c|c|c|c|c|c|c|c|c|c|}
\hline \multirow[b]{2}{*}{ Characteristic } & \multicolumn{3}{|c|}{1981 Census } & \multicolumn{3}{|c|}{1998 Census } & \multicolumn{3}{|c|}{$\begin{array}{c}\text { 2006-07 Labor Force } \\
\text { Survey }\end{array}$} \\
\hline & Total & Male & Female & Total & Male & Female & Total & Male & Female \\
\hline Pakistan & 26.17 & 35.05 & 15.99 & 43.92 & 54.81 & 32.02 & 55.0 & 67.0 & 42.4 \\
\hline Rural & 17.33 & 26.24 & 7.33 & 33.64 & 46.38 & 20.09 & 46.2 & 60.8 & 31.2 \\
\hline Urban & 47.12 & 55.32 & 37.27 & 63.08 & 70.00 & 55.16 & 71.1 & 78.2 & 63.5 \\
\hline Balochistan & 10.32 & 15.20 & 4.32 & 24.83 & 34.03 & 14.09 & 44.0 & 61.1 & 23.3 \\
\hline NWFP & 16.70 & 25.85 & 6.48 & 35.41 & 51.39 & 18.82 & 49.0 & 68.5 & 30.2 \\
\hline Punjab & 27.42 & 36.82 & 16.81 & 46.56 & 57.20 & 35.10 & 56.1 & 65.7 & 46.4 \\
\hline Sindh & 31.45 & 39.74 & 21.64 & 45.29 & 54.50 & 34.78 & 57.6 & 70.2 & 43.4 \\
\hline
\end{tabular}

Source: Census data (www.statpak.gov.pk/depts/pco/statistics/other_tables/literacy_ratio.pdf) and 2006-07 Labor Force Survey (Pakistan Federal Bureau of Statistics). July 2008. 
percent increase in the probability of contraceptive use. The study emphasized the importance of triggering demand for fertility change through opportunities for investing in the schooling of boys and girls and of bringing equity to the supply of girls' primary schools, village by village.

\section{Women's Labor for Participation and Autonomy}

Women's status has an important influence on fertility rates, though the relationship is particularly complex in Pakistan. Women's status is extremely low in Pakistan, which ranks 126 out of 128 countries on the Gender Gap Index as measured by education $\left(123^{\text {rd }}\right)$, opportunities for economic participation $\left(126^{\mathrm{th}}\right)$, health and survival $\left(121^{\mathrm{st}}\right)$, and political empowerment $\left(43^{\text {rd }}\right){ }^{49}$

In Pakistan, opportunities for women to work in the formal sector are limited. Only 19 percent of women older than age 10 are employed in the formal sector, about a quarter of the rate for men (70 percent). ${ }^{50}$ Adding informal sector employment more than doubles women's labor force participation ( 41 percent), which has risen rapidly since 2001-02 (26 percent). ${ }^{51}$ The highest rate is reported for NWFP (56 percent), followed by Balochistan (49 percent); women's participation is lowest in Sindh (36 percent). About 20 percent of women in the informal sector are unpaid family workers. Labor force participation is highest among women with no education or with a secondary or higher level of education. Women with no education and in rural areas are likely to be engaged in unpaid work, while women in urban areas and with a higher level of education tend to be engaged in paid work.
The relationship between women's labor participation, decision-making power, and reproductive behavior is complex in Pakistan. Use of any contraceptive method is highest among women who worked only after marriage (38 percent) or who never worked (30 percent) and lowest among currently working women (29.2 percent)..$^{52}$

A multivariate analysis shows that women's increased participation in household decision-making positively is associated with lower fertility outcomes, though it is strongly conditioned by socio-economic and demographic factors. ${ }^{53}$ The study also found a strong positive link between women's freedom to travel outside the home alone and their domestic decision-making power, especially in rural areas. The study concluded that good spousal communication had a strong effect on contraceptive use and desired childbearing for both rural and urban women.

Another study confirmed the ambiguous relationship between women's labor participation and autonomy. ${ }^{54}$ It found that rural women's earned income had no effect on decisions such as use of family planning. In contrast, a study of women in northern Punjab concluded that women's work (especially paid employment), age, and family structure appear to be linked to women's increased decision-making power and autonomy in the household. ${ }^{55}$ It found that Northern Punjabi women have less economic autonomy but greater mobility and decision-making power than women in Southern Punjab.

A study based on interviews with 1,842 married women in India and 1,036 in Pakistan found that region of residence also plays a major conditioning role after controlling for religion and that the influence of traditional 
factors conferring status on women remained strong. ${ }^{56}$ Women's education and employment were not found to enhance women's autonomy. The study emphasized the need for context-specific and comprehensive strategies to enhance women's autonomy beyond education, employment, and delayed marriage, such as enabling women to mobilize and access community resources and public services and providing support to challenge traditional norms.

\section{Religion and Religious Leadership}

Pakistan's main religion, Islam, strongly influences family planning. Although Islamic scriptures do not proscribe family planning ${ }^{57}$, most religious parties and many religious leaders oppose it.

Most respondents in a study of religious influence on attitudes toward family planning said that while they did not know whether Islam permits use of contraception, they believe that Islam opposes the norm of small families and use of family planning to space births. ${ }^{58}$ The main reason given by married women for not using contraception was that having children is "up to God." The study concluded that the high degree of fatalism underlying such thinking and the belief that Islam prohibits family planning are behind the high fertility levels in Pakistan.

A study in rural Pakistan found that most men ( 89 percent) believed that religious leaders opposed fertility control. ${ }^{59}$ Respondents suggested that religious leaders must be involved if reproductive health programs are to be effective in rural areas. Information programs explaining that the Qur'an and Hadith are not against fertility control, along with examples of family planning programs in other Muslim countries, were proposed as one way to change attitudes among religious leaders.

\section{Role of Men and Spousal Communication}

In Pakistan, where women are generally subordinate to men, studies repeatedly identify the husband's agreement as one of the most influential determinants of the acceptance of family planning in both rural and urban areas. ${ }^{60}$ A study in Naushahro Feroze District, Sindh, using multivariate analysis found that use of family planning is five times more likely if a woman receives her husband's approval. ${ }^{61}$ Another study in an urban slum found that women were 10 times more likely to use family planning methods if their husband approves. $^{62}$

Related to the notion of a husband's approval of family planning is the importance of good spousal communication, something many studies find lacking in Pakistan. ${ }^{63}$ One study revealed that women believed their husbands to have more negative views toward family planning than was true, highlighting the value of spousal communication to dispel such misperceptions. ${ }^{64}$ Another study found a strong positive relationship between spousal communication and contraceptive use or desired family size for both urban and rural women. ${ }^{65}$

To make sound decisions, husbands need information about women's reproductive health, yet many family planning programs are directed only to women. There are misconceptions and large gaps in knowledge among men on a range of reproductive health issues. One study found that 93 percent of men wanted more information on family planning 
and showed a willingness to become partners in their wife's reproductive health. ${ }^{66} \mathrm{~A}$ rising share of Pakistani men is strongly motivated to fulfill their family's fertility preferences through contraceptive use. ${ }^{67}$

As further evidence of husbands' willingness to engage in family planning, half of couples nationwide practicing family planning use methods that require male cooperation (condom, rhythm, and withdrawal). ${ }^{68}$ The rising use of withdrawal reflects growing demand for family planning and gaps in the availability and quality of family planning services. ${ }^{69}$ In addition, withdrawal seems to be widely accepted because of fear of modern contraceptive methods and their side effects and strong religious beliefs that other methods are prohibited. ${ }^{70}$ Because withdrawal has a high failure rate, however, it remains critical to increase knowledge about contraceptives and their side effects and to make a wide range of contraceptive methods available. 


\section{Government Population Policy and the Family Planning Service Provision - An Early but Slow Start}

P akistan was one of the first countries to acknowledge the negative impact of rapid population growth on economic and social development, as noted in its first Five-Year Plan of 1955-60. Each successive plan has continued to do so, emphasizing the need to control population growth through family planning programs. Follow-up lagged, however, likely reflecting the lack of political commitment. A critical limitation of Pakistan's population policy, according to one study, is that it failed to comprehensively define a program linking development efforts and population planning. ${ }^{71} \mathrm{~A}$ review of population policies since the 1960s concluded that no significant gains have been made toward the targets defined in various plans, because population was not integrated into the development planning process and so the pressures it would exert on social and economic sectors were not taken into account. ${ }^{72}$

Pakistan's first population policy, announced in 2002, saw fertility reduction as part of a wider poverty-reduction and sustainable development strategy that also addressed gender inequality. Proposed strategies for achieving population stability by 2020 included addressing the unmet need for con- traceptives, mounting advocacy campaigns, targeting underserved groups, introducing a cadre of male mobilizers, improving mobile service units, building population-centered services, involving the private sector and nongovernmental organizations (NGOs), strengthening collaboration among ministries and departments, and decentralizing management to provinces and districts.

Despite the early recognition of population issues, political support and commitment has been inconsistent, undermining implementation. ${ }^{73}$ Family planning policies fell victim to divisive domestic politics, resulting in inadequate budget allocations and hesitation by the international community to support family planning activities. President Ayub Khan (1958-69) was the first head of state to publicly address the need for family planning despite strong opposition from religious leaders. But later presidents relegated family planning programs to the background, especially Muhammad Zia ul-Haq (1977-88), whose support base was led by the conservative Jamaat Islami, which opposed a national family planning program. Only during Benazir Bhutto's second term in office during the mid-1990s, did family planning gain open political support. 


\section{Institutional Structure of the Family Planning Service Provision System}

During the Second Five-Year Plan, 1960-65, a Family Planning Wing was established under the Ministry of Health, Labor, and Social Welfare, with a focus on clinic-based interventions. Under the Third Five-Year Plan, 1965-70, the population program was separated from the health program and transferred to the Ministry of Planning and Development as the Population Welfare Division. During the Sixth Five-Year Plan, 1983-88, provincial population welfare departments were established, and field activities were transferred to the provinces. The Population Welfare Division received ministry status during the Seventh Five-Year Plan, 1988-93. Meanwhile, the Ministry of Health seemed to distance itself from responsibility for promoting family planning through its facilities. A 1998 study by the United Nations Population Fund recommended merging the ministries, and the government made plans to do so following internal discussion in $2001 .^{74}$ The two ministries resisted merger, and, as a result, the parallel structures were maintained.

\section{Administrative structure of the Ministry of Pop- ulation Welfare and Ministry of Health. The} federal and provincial structures of both ministries are similar. Responsibilities are divided between the federal government (ministries) and the four provincial governments (departments) headed by secretaries. Both ministries have district and tehsil (county) level administrative units and service outlets. However, the Ministry of Population Welfare's program planning and implementation are centralized, and the ministry controls the flow of funds.
Provinces are responsible for program implementation, but employees in the provinces are federal government employees. In contrast, the provincial departments of health have considerable autonomy. They set their own priorities, plan programs, and use revenues generated in the province.

Collaboration between the Ministry of Population Welfare and Ministry of Health. These differences in administrative structure and functioning make merger unlikely. One study noted several incompatibilities: different sources of funding and channels for fund flows and controls; different hierarchical and administrative relationships within each sector, with population welfare only partially defederalized and health almost completely devolved; institutional inability to scale up family planning service delivery at health outlets despite several high-level directives over the years; and staff opposition as merger could threaten established career paths. ${ }^{75}$

The report also pointed out areas of cooperation between the ministries, particularly in service delivery, requisitioning and distribution of contraceptives, and training to promote efficiency and noted other areas for potential collaboration in service delivery: the lady health workers, mobile services, and clinical family planning services at health facilities. Considering that family planning is not viewed as part of health services in rural and underserved areas and has been culturally stigmatized, the potential for maximizing synergies appears to be greatest for integrating family planning services and basic health services through existing Lady Health Worker Program (see section on innovations in government family planning services for more 
detail on lady health workers). For sustainable and meaningful collaboration to succeed, however, will require removing impediments that lady health workers face at the field level. Workers are already overburdened in delivering regular health services, leaving them little time to provide family planning services. Training in providing family planning services is also required. And because the lady health workers report to officers of the Ministry of Health and provincial department of health, Ministry of Population Welfare officers have little influence over their performance.

\section{The Government Sector Service Delivery System for Family Planning}

The Ministry of Population Welfare provides services through an extensive network of institutions in urban and rural areas. In 2008 the ministry had 2,740 Family Welfare Centers, 176 Reproductive Health Service Centers-A, 117 Reproductive Health Service Centers-B, and 292 Mobile Service Units. Family Welfare Centers provide family planning and maternal and child health services. They distribute condoms, oral contraceptives, IUDs, and injectables. Each center serves about 6,000 people. $^{76}$ Reproductive Health Service Centers are attached to service outlets in major hospitals. The "A" centers provide a full range of contraceptives, contraceptive surgery, and maternal and child health services. The "B" centers include well established hospitals with fully equipped operating facilities such as district/tehsil headquarter hospitals, NGOrun clinics, and private hospitals. In remote areas, 292 Mobile Service Units each cover some 30,000 people, providing two to three extension camps for family planning services each week, then returning to each village a month later.

As part of the integration of family planning services within basic health services now in progress, the Ministry of Health provides family planning services through lady health workers, who provide oral contraceptives and condoms and make referrals to health facilities for contraceptive surgery. The ministry also provides services at some 12,500 health outlets, government hospitals, dispensaries, basic health units, rural health centers, and maternal and child health centers as part of comprehensive maternal, neonatal, and child health services. ${ }^{77}$ Service provision is often constrained by lack of staff knowledge, inadequate attention to family planning, and frequent stock-outs of contraceptive commodities at health outlets.

\section{Role of the Private Sector and Nongovernmental Organizations}

Private sector involvement in family planning has historically been limited in Pakistan, except for an ongoing social marketing program (see section on innovation in government family planning programs). Past family planning programs failed to involve the private sector in large-scale government programs. ${ }^{78}$

NGOs, in contrast, have a longer history of family planning activities in Pakistan. Though government support was sometimes lukewarm, NGO family planning activities have not generally been restricted. ${ }^{79}$ The Ministry of Population Welfare has acknowledged the contributions of NGOs to promoting population programs. The government now provides grant financing to NGOs from bilateral donor funding. ${ }^{80}$ There are several well established NGOs in Pakistan delivering 
family planning services, such as the Family Planning Association of Pakistan; Pakistan Voluntary Health and Nutrition Association; All Pakistan Women's Association, an umbrella organization with more than 40 NGOs; and the Marie Stopes Society.

Following the International Conference on Population and Development in Cairo in 1994, a nonprofit national umbrella organization, the National Trust for Population Welfare (NATPOW), was established to strengthen NGO capacity in population welfare, reproductive health, maternal and child health, and community participation. Despite having more than 600 affiliated NGOs, it has remained relatively ineffective.

\section{Status of the Family Planning Services}

The public sector remains the main source of contraceptives. In 2001-02, more than half of women who used modern contraceptives obtained them from government facilities and health workers, while 20 percent received them through the private sector and NGOs and 13 percent from other facilities. ${ }^{81}$ The picture was roughly the same in 2006-07, with 48 percent of modern method users relying on the government sector, 30 percent on the private sector, and 12 percent on other facilities. ${ }^{82}$ The public sector is the main provider of female sterilization (72 percent), while condoms are provided mainly through the private sector and other sources. Oral contraceptives, injectables, and IUDs are provided almost equally by the public sectors and the private sectors/ other sources.

Families in rural areas rely almost exclusively on public sector facilities for family planning services, including community-based workers and fixed outlets, while urban populations have more options, including social marketing projects, which provide contraceptives through a large network of outlets at subsidized prices.

Underutilization of government facilities has been a concern across population groups and health services. People either do not go to these facilities or, having gone, are dissatisfied with the services and do not return. Only 12 percent of households in rural and urban areas are satisfied with government family planning services, while 35 percent are satisfied with basic health unit services. ${ }^{83}$

A 1998-99 evaluation of family welfare centers reported the following findings on quality of service and performance: ${ }^{84}$

$\rightarrow 343$ new acceptors on average were registered in the first half of 1997; of those, only a third was traceable (the survey found that numbers were often exaggerated to meet targets).

$\rightarrow 30$ percent of centers reported stock-outs of contraceptives of one month.

$\rightarrow 10$ percent of centers had no family welfare workers.

$\rightarrow 59$ percent of centers reported that another center also provided family planning services in the same village.

$\rightarrow 30$ percent of centers had no informational material, and 30 percent of centers with such material never distributed it.

$\rightarrow 17$ percent of clients received no information on the benefits and side effects of contraceptives offered.

$\rightarrow 48$ percent of dropouts never received a home visit by a family welfare worker to encourage restarting contraceptive use. 
$\rightarrow$ Half of family welfare workers reported no supervision visits in the past six months.

According to 2001-02 survey data, less than half ( 46 percent) of health facilities (dispensaries, reproductive health services centers, and basic health units) had stocks of contraceptives. ${ }^{85}$

Clients' complain that distance barriers, especially in rural areas, prevent use of family planning services. For example, 57 percent of survey respondents noted that the nearest maternal and child health center distributing contraceptives was 10 or more kilometers from the village, and 41 percent reported that the nearest family welfare center was that far away. ${ }^{86}$

Cultural constraints also limit women's mobility in Pakistan. Because of the custom of women's seclusion (purdah), women must be accompanied by another family member when they travel outside their village. One study found that only 20 percent of rural women said that they would be able to visit a hospital by themselves. ${ }^{87}$ Government actions to address these barriers, through community-based service provision or more village outlets could help to increase contraceptive prevalence in rural areas.

Cost is another barrier to contraception use, especially for the poor. While the Ministry of Health does not charge for contraceptive services, the Ministry of Population Welfare does-Rs. 0.5 per condom and Rs. 3 for oral contraceptives (per cycle), IUDs, and injectables (per unit). The effect of price on contraception use is particularly evident for condoms and injectables, many of them supplied by the private sector. ${ }^{88}$ In 2000, the Multi-Donor Support Unit of the Social Action Program Project (see box 2 later in this report) issued a note on pricing reproductive health services, concluding that a small fee for all family planning services (a standard fee of Rs. 10.00 per couple per year was suggested), with small incremental increases, would not affect demand. The report recommended reducing travel time to build demand and reduce price elasticity, providing poor couples with adequate contraceptives at public facilities, and ensuring that all Ministry of Health outlets offer family planning services. ${ }^{89}$

\section{Government Financing of Population Programs}

Government spending on population programs has increased gradually since the late 1980s, with some slippage in 1996/97 and 2000-02. Spending rose from Rs. 415 million in 1990 to Rs. 8,965 million in 2005/06 (latest available data), nearly double the 2004/05 amount. Spending has been somewhat erratic, however, unlike health sector spending, which has increased steadily (figure 6). Nevertheless, population programs as a share of total government spending have increased sharply, though from a low base, from 0.16 percent in 1990 to 0.45 percent in 2000 and 0.61 percent in 2005 (table 6). And despite the economic downturn, government spending on population and health increased under the Social Action Program (SAP-I and II). These funding increases since the late 1980s likely contributed to the increase in contraceptive use and the decline in the total fertility rate. 

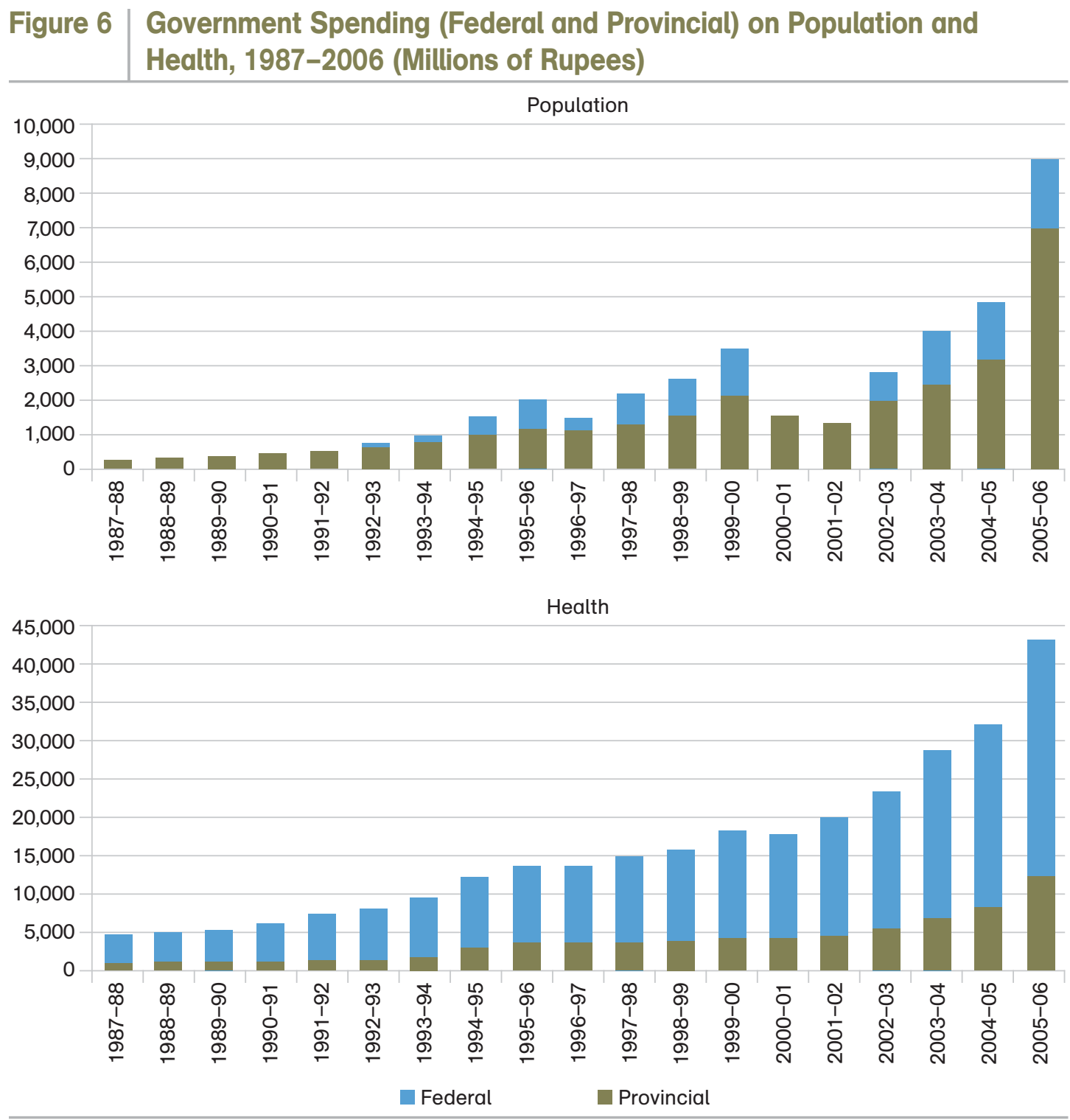

Source: Calculated by the World Bank based on the data from the Accountant General of Pakistan.

Table 6 Government Expenditure on Population and Health and Average Annual Growth, 1990/91-2005/06 (percent)

\begin{tabular}{lcccccc}
\hline & \multicolumn{3}{c}{$\begin{array}{c}\text { Share of total government expenditure } \\
\text { (percent) }\end{array}$} & \multicolumn{3}{c}{ Average annual growth (percent) } \\
\cline { 2 - 7 } & $1990 / 91$ & $2000 / 01$ & $2005 / 06$ & $1987 / 88-$ & $1990 / 91-$ & $2000 / 01-$ \\
& 0.16 & 0.45 & 0.61 & 27.9 & 26.5 & 42.1 \\
\hline Population sector & 2.06 & 2.36 & 2.90 & 7.1 & 12.9 & 19.4 \\
\hline Health sector & & & &
\end{tabular}

Source: Calculated by the World Bank based on the data from the Accountant General of Pakistan. 


\section{Pakistan's Innovative Family Planning Programs}

Both the government and the private and NGO sectors have introduced new initiatives in family planning programs over the years.

\section{Innovations in Government Family Planning Programs}

Under the Eighth Five-Year Plan (1993-98), the government launched two communitybased programs in family planning: the Village-Based Family Planning Worker scheme (VBFPW) under the Ministry of Population Welfare in 1992/93 and the Lady Health Worker Program (LHWP) under the Ministry of Health in $1994 / 95$. The idea was to bring family planning programs directly to women in rural areas, who were generally unable to leave their homes or villages to travel alone to family planning facilities.

The VBFPW scheme planned to cover 13,500 villages in all provinces by basing female workers in their own village. This scheme borrowed many elements from the successful Family Welfare Assistant scheme in Bangladesh. An evaluation in 2000 concluded that the VBFPW scheme "has become the pivot of activities of the Ministry of Population Welfare in rural areas." ${ }^{90}$ Contraceptive prevalence in program areas was 41.8 percent, significantly higher than the national average reported in the Pakistan Demographic and Health Survey. The evaluation report did not analyze baseline data, so there is no way to know whether the high contraceptive use rate can be attributed to the VBFPW.

The evaluation also found some management and implementation problems. For instance, nearly all women who participated in the evaluation confirmed a visit by a family planning worker in the past, but only about half reported a visit in the month prior to the survey (the recommended schedule of visits is once a month). Moreover, while almost all workers were aware of their duty to provide family planning information and methods to users, only 60-70 percent understood that they were also supposed to inform users of contraceptive side effects and follow up with new acceptors. Another program evaluation concluded that the scheme was a major contributing factor to the increase in contraceptive use in the villages studied and found a strong relationship between the use of contraceptives and the intensity of family planning worker visits. ${ }^{91}$

The LHWP, under the Ministry of Health, was developed to provide low-cost preventive services for communicable diseases and maternal and child health services, including family planning (lady health workers distribute oral contraceptives and condoms) to the entire population. The program's recruitment criteria, training, remuneration, 
supervision, and method of service delivery were almost identical to those adopted by the VBFPW program. By July 2005, there were about 88,000 lady health workers and supervisors nationwide. One study found that women in rural areas served by lady health workers were more likely to use a modern and reversible contraceptive method than were women with no access to services. ${ }^{92}$ However, the LHWP tends to serve more advantaged areas that are already slightly over-served and have a nearby functional health facility. To succeed, the program needs to reach out to the most underserved populations in rural areas, where contraceptive use is still very low. (See the detailed information on the program evaluation in annex 1.)

Both programs have run into serious management problems at the field level, including lack of effective coordination, duplication of services, contraceptive stock-outs, and lack of local ownership. ${ }^{93}$ The 2000 program evaluation of the VBFPW program found that nearly half ( 47 percent) of the 43 percent of VBFPW respondents who reported that there was also a lady health worker in the village claimed that her presence hampered their activities. In June 2002, following the recommendations of a task force reviewing the performance of population programs, a decision was made to merge the two programs; the LHWP is now also responsible for providing family planning services at the household level in rural communities.

These government-sponsored community health worker programs grew into one of the largest community approach schemes in the world. Though improvements in service provision are still needed to achieve better outcomes, this innovative community-based approach holds great promise for increasing contraceptive coverage in rural areas.

\section{Innovations in NGO and Private Sector Programs Supported by Donors}

Social marketing has been a bright spot in Pakistan's family planning activities. The U.S. Agency for International Development (USAID) launched support for a condom social marketing campaign in the mid1980s through the Social Marketing Pakistan (SMP) program with technical assistance from the NGO Population Services International. The project distributed some 354 million Sathi brand condoms until March 1994, when USAID funding ended. Other donors moved in to provide support, such as KfW (the German Development Bank), the U.K. Department for International Development (DFID), and UN organizations such as the United Nations Population Fund (UNFPA) (see box 1 for a summary of international donor support for population programs in Pakistan and box 2 for World Bank support.) USAID resumed support after 2001.

KfW has supported social marketing since 1995 under the Greenstar model. Greenstar Social Marking Pakistan (GSMP) has expanded its contraceptive options to include oral contraceptive, IUDs, and injectables. Product distribution is undertaken by SMPcertified service providers and outlets, including doctors, paramedics, and chemists. Coverage is mainly in urban and peri-urban areas. Greenstar products are priced based on market research.

DFID supported social marketing of oral contraceptives and injectables from 1996 to 2001 under the Key Social Marketing (KSM) 


\section{Box 1 Role of International Donors:}

External funding for population assistance to Pakistan (programs and research for family planning, reproductive health, and HIVIAIDS) has fluctuated widely over the past decade. Donor funding specifically for family planning activities, has declined considerably over the 2000s, with average annual assistance falling almost in half, from \$12.9 million during 1996-2000 to \$6.7 million during 2001-05.

The Ministry of Population Welfare lists five key donors to population welfare programs in recent years: World Bank (see box 2 for an overview of World Bank assistance to the population sector), the Asian Development Bank, United Nations Population Fund (UNFPA), U.K. Department for International Development, and the German Development Bank (KfW). The United Kingdom, Germany, and the Netherlands have provided consistent financial assistance since the 1990s, while the United States has a long, if intermittent, history of support, with a large increase in assistance since 2005.

In recent years, USAID has increased its assistance to maternal and child health programs, including family planning, in Pakistan. The five-year (2004-09) Pakistan Initiative for Mothers and Newborns (PAIMAN) provided a package of comprehensive maternity care in 11 districts and benefits more than 2.8 million married couples. The five-year (2007-12) Family Advancement for Life and Health (FALAH) project focuses on pregnancy spacing as a key health intervention to improve the survival and health of mothers and children. The project also trains providers and increases access to quality services in the public and private sectors. Greenstar Social Marketing Pakistan is a partner of both projects, offering its expertise in private sector approaches.

Source: Hardee and Leahy 2008; Ministry of Population Welfare (http://www.mopw.gov.pk/); Organisation for Economic Co-operation and Development (OECD) Development Assistance Committee (DAC) database (http://stats.oecd.org/ Index.aspx?DatasetCode=ODA_RECIP).

Note: Figures reported in the OECD/DAC database, especially for multilateral donors, are often underreported.

program. KSM contracted with a manufacturer to produce, package, and distribute its Key products to enlisted retailers. Price was based on market research.

The social marketing projects seek to expand coverage of family planning services in urban areas, develop a cadre of skilled personnel, satisfy the unmet need for contraceptives, and accustom people to paying for services. The two projects have established a network of more than 56,000 outlets and service facilities in urban and peri-urban areas, a great leap forward in the accessibility of family planning services. GSMP reported that more than 16,000 private health care providers were registered with the Greenstar health care providers network as of 2005-06. These social marketing projects adopted creative approaches to building sustained demand for contraceptive products. Their promotional campaigns complemented government efforts but used original and focused messages on TV, radio, cinema, newspapers, and other information media. The campaigns increased the visibility of family planning products and provided information on proper use, prices, and sources of supply.

Today, GSMP and KSM together provide a third ( 30 percent by GSMP and 3 percent by KSM) of all modern contraceptives in Pakistan, while the public sector delivers 59 percent, according to GSMP. ${ }^{94}$ The share is higher for condoms, with 78 percent of urban condom users reporting using a social marketing brand..$^{95}$

Though the impact of social marketing on fertility reduction in urban areas has not been rigorously studied, it appears that social marketing projects might have contributed 


\section{Box 2 World Bank Assistance to the Population Sector in Pakistan}

The World Bank has supported population issues in Pakistan through policy dialogue with the government (Poverty Reduction Strategy Papers and the Country Assistance Strategy) and through direct assistance on the following projects since 1983:

- Population Project (1983-89, US\$18.0 M).

- Social Action Program Project I (1993-97, US\$200 million).

- Social Action Program Project II (1998-03, US\$250 million).

- Family Health Project I (1992-99, US\$45.1 million).

- Family Health Project II (1994-99, US\$48.0 million).

- Population Welfare Program Project (1996-2000, US\$65.1 million).

- Northern Health Project (1996-2000, US\$26.7 million).

In 1992, Pakistan launched the Social Action Program (SAP), a broad-based social sector reform program to improve the access to and quality of basic social services in four sectors including population welfare. Several donors, including the World Bank, the Asian Development Bank, the U.K. Department for International Development, and the Government of the Netherlands, supported the SAP through the Social Action Program Project (SAPP-I, 1993-97). A follow-on SAPP-II (1998-2003) built on the lessons of the first project. Taking a sector-wide approach to key underlying institutional issue, the projects aimed to increase government spending on basic social services; build government capacity for planning, monitoring, and implementing social service programs; and encourage NGO and private sector participations.

The two projects appear to have protected social sector and SAP budget allocations during 1993-97 from the drastic cuts made in other public programs. The projects also created a supportive institutional policy framework for the health sector and provided a common tool for policy dialogue between the government and donors. Policy issues addressed through the projects included providing family planning services through health outlets, improving coordination between population and health facilities, training health staff in family planning, and supplying contraceptives to health outlets.

SAPP-I and II helped create an enabling environment for other population-related projects implemented in the 1990s: Family Health I (NWFP and Sindh) and II (Balochistan, Punjab Islamabad Capital Territory), Population Welfare, and Northern Health. These projects aimed to increase contraceptive use by integrating family planning into primary health services, increasing demand for contraceptives through information activities, training health personnel, increasing contraceptive supplies at health outlets, and supporting the private sector. Contraceptive prevalence nearly doubled in all provinces over the course of the projects.

No systematic impact evaluations were conducted to isolate the impact of Bank-assisted population projects, it is thus not possible to attribute increased contraceptive use or declining fertility directly to the projects. However, the period of intensive Bank support coincided with the period of rapid increase in contraceptive prevalence and decline in the total fertility rate after decades of sustained high fertility.

Source: World Bank 1990, 1998, 2003, 2000a, 2000b, 2000c, 2001.

to higher contraceptive prevalence rates and fertility reduction. The analysis on fertility and contraceptive changes in urban Pakistan during the 1990s to explore the role played by social marketing initiative provides the following results: (1) the decline in urban fertility level was less erratic and a bit faster in the second half of 1990s, (2) there was a steady rise in CPR since the early 1990s and reached around $40 \%$ percent by 2000 , (3) the most reported method by urban couples was condom, and (4) there was a significant rise in the use of oral pills and injectables during $1996-2001 .{ }^{96}$ 
Table 7 Trend in Total Fertility Rate and Contraceptive Prevalence Rate During 1990s

\begin{tabular}{lcccc}
\hline & \multicolumn{2}{c}{ Total fertility rate } & \multicolumn{2}{c}{ Contraceptive prevalence rate } \\
\hline Year & Urban & Rural & Urban & Rural \\
\hline $1990 / 91$ & 4.9 & 5.6 & 25.7 & 5.8 \\
\hline $1994 / 95$ & - & - & 32.0 & 11.0 \\
$1996 / 97$ & 4.3 & 5.9 & 36.5 & 18.6 \\
$2000 / 01$ & 3.7 & 5.4 & 39.6 & 21.7 \\
\hline
\end{tabular}

Source: Ahmed 2002.

The challenges ahead include addressing unmet need in urban areas, supporting reproductive health approaches, linking social marketing programs with other private sector programs and public sector population pro- grams, and promoting local manufacturing. ${ }^{97}$ In addition, using social marketing schemes to increase coverage in rural areas should be considered to help fill the gap in contraceptive availability. 


\section{Implications}

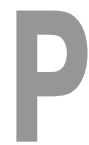
akistan's complex history of population programs is a lesson for its planners as well as other high-fertility countries.

During the 1990s, as family planning services improved, contraceptive prevalence rates more than doubled and the total fertility rate fell an estimated 40 percent. Two innovative community-based programs begun in the 1990s and the involvement of the private sector in family planning through the Greenstar Network social marketing initiative likely had consider- able impact on fertility rates. However, the programs have several shortcomings, and Pakistan has made little progress in reducing sociocultural constraints to family planning (related to religion, gender, and rural-urban division). The government needs to address program shortcomings immediately to meet high level of unmet needs for contraceptives. In parallel, underlying socio-cultural constraints should be improved to accelerate fertility reduction in the long run. 


\section{Annex 1. Evaluation of the Lady Health Worker Program}

n 2002, Oxford Policy Management conducted an evaluation of the Lady Health Worker Program (LHWP) covering 19992002, assessing the effectiveness and impact of the program, especially among underserved groups. ${ }^{98}$

\section{Implementation Issues}

The program has been implemented under the Ministry of Health since 1994/95. Though planned at Rs.9.1 billion over five years, actual levels of funding have been considerably lower. The amount spent on drugs and contraceptives per lady health worker was 84 percent lower than planned, salaries have fallen 20 percent in real terms, and real unit cost per lady health worker fell 51 percent from $1994 / 95$ to $2000 / 01$.

This severe underspending likely undermined the effectiveness and impact of the program. Undersupply of contraceptives was especially critical; 38 percent of lady health workers were without condoms and 67 percent were without oral contraceptives at the time of the survey. Only 32 percent of workers had been paid in the month prior to the survey, and 34 percent had not been paid for more than three months. And 20 percent of workers received salaries below what they were entitled to.

\section{Characteristics of Lady Health Workers}

Lady health workers are contract employees. They must be married, age 20-50, have at least eight years of schooling, and live and work in the communities they serve. They receive both full-time and in-service training. The supervision system appeared to be functioning well: 70 percent of lady health workers reported that they had had a supervision meeting in the month before the survey. Lady health workers are supported by nearby firstlevel care facilities.

On average, lady health workers make 25 household visits and see 20 clients a week. The workload is lowest in Sindh and Balochistan. Around 40-50 percent of eligible families have received services (not limited to family planning). Service levels are highest in Azad Jammu and Kashmir and Northern Areas and lowest in Balochistan. Lady health workers provide 40 percent of total contraceptives in Balochistan, as they are assumed to be the main source of contraceptive supply. Though the level of knowledge of lady health workers was fairly good, only 20 percent of them provided eligible couples with information related to family planning. High performing workers had higher levels of knowledge and were more likely to receive supervision and supplies. The 
Pakistan Demographic and Health Survey of 2006-07 found that lady health workers reached only 23 percent of nonusers of contraceptives to discuss family planning issues. Of those contacted, only 9 percent had received information on family planning, 3 percent had received family planning supplies, and 2 percent had received a referral to a health facility in the previous 12 months.

\section{Outcomes and Impacts of the Program}

Overall, areas served by lady health workers have better health indicators than control populations and the national average. However, lack of baseline data precluded establishing whether the differences were due to the program or to other differences between program and control areas, such as socioeconomic in- dicators. Nonetheless, lady health workers appear to have affected the provision of family planning. Use of any contraceptive method was 30 percent in program areas compared with 21 percent in control areas and 22 percent for the national average, and use of any modern method was 20 percent in program areas, 14 percent in control areas, and 15 percent for the national average.

\section{Limitation of the Evaluation}

The evaluation compared program and control areas at the time of the survey, because it did not collect baseline data on health status in program and control population groups at the beginning of the intervention. In addition, the evaluation did not assess program impact on the fertility rate or the infant mortality rate because the rate of change was too slow. 


\section{Annex 2. Country-at-a-Glance: Pakistan}

\begin{tabular}{|c|c|c|c|c|}
\hline \multirow[b]{2}{*}{ Indicator } & \multicolumn{2}{|c|}{ Earliest available data } & \multicolumn{2}{|c|}{ Latest available data } \\
\hline & Value & Year & Value & Year \\
\hline \multicolumn{5}{|l|}{ Economy } \\
\hline $\begin{array}{l}\text { GNI per capita (World Bank Atlas method, cur- } \\
\text { rent US\$) }\end{array}$ & 330 & 1980 & 800 & 2006 \\
\hline $\begin{array}{l}\text { GNI per capita (purchasing power parity, current } \\
\text { international \$) }\end{array}$ & 620 & 1980 & 2,410 & 2006 \\
\hline Poverty gap at national poverty line (percent) & 7 & 1999 & 7 & 1999 \\
\hline \multicolumn{5}{|l|}{ Demography } \\
\hline Population, total & $82,730,331$ & 1980 & $159,002,039$ & 2006 \\
\hline Population growth (annual percent) & 2.9 & 1980 & 2.1 & 2006 \\
\hline Population ages 0-14 (percent of total) & 42.7 & 1980 & 36.4 & 2006 \\
\hline Urban population (percent of total) & 28.1 & 1980 & 35.3 & 2006 \\
\hline Fertility rate, total (births per woman) & 7.0 & 1980 & 3.92 & 2006 \\
\hline $\begin{array}{l}\text { Adolescent fertility rate (births per } 1,000 \text { women } \\
\text { ages 15-19) }\end{array}$ & 68.84 & 1997 & 32.89 & 2006 \\
\hline Life expectancy at birth, female (years) & 55.7 & 1980 & 65.8 & 2006 \\
\hline Mortality rate, infant (per 1,000 live births) & 110 & 1980 & 77.8 & 2006 \\
\hline Mortality rate, under-five (per 1,000 live births) & 153 & 1980 & 97.2 & 2006 \\
\hline $\begin{array}{l}\text { Maternal mortality ratio (modeled estimate, per } \\
100,000 \text { live births) }\end{array}$ & 320 & 2005 & 320 & 2005 \\
\hline \multicolumn{5}{|l|}{ Health } \\
\hline Health expenditure, total (percent of GDP) & 2.3 & 2001 & 2.1 & 2005 \\
\hline Health expenditure, public (percent of GDP) & 0.5 & 2001 & 0.4 & 2005 \\
\hline Health expenditure per capita (current US\$) & 10 & 2001 & 15 & 2005 \\
\hline $\begin{array}{l}\text { Immunization, measles (percent of children ages } \\
12-23 \text { months) }\end{array}$ & 1 & 1980 & 80 & 2006 \\
\hline $\begin{array}{l}\text { Malnutrition prevalence (weight for age, percent } \\
\text { of children under five) }\end{array}$ & 39.0 & 1991 & 31.0 & 2001 \\
\hline $\begin{array}{l}\text { Births attended by skilled health staff (percent of } \\
\text { total) }\end{array}$ & 18.8 & 1991 & 31 & 2005 \\
\hline $\begin{array}{l}\text { Contraceptive prevalence (percent of women } \\
\text { ages 15-49) }\end{array}$ & 11 & 1984 & 27.6 & 2001 \\
\hline
\end{tabular}




\begin{tabular}{|c|c|c|c|c|}
\hline \multirow[b]{2}{*}{ Indicator } & \multicolumn{2}{|c|}{ Earliest available data } & \multicolumn{2}{|c|}{ Latest available data } \\
\hline & Value & Year & Value & Year \\
\hline Nurses and midwives (per 1,000 people) & 0.45 & 2005 & 0.45 & 2005 \\
\hline Physicians (per 1,000 people) & 0.29 & 1980 & 0.80 & 2005 \\
\hline \multicolumn{5}{|l|}{ Education } \\
\hline $\begin{array}{l}\text { Literacy rate, adult female (percent of women } \\
\text { ages } 15 \text { and older) }\end{array}$ & 26 & 1996 & 35.4 & 2005 \\
\hline $\begin{array}{l}\text { School enrollment, secondary, female (percent } \\
\text { net) }\end{array}$ & 22.9 & 2003 & 25.8 & 2006 \\
\hline School enrollment, primary, female (percent net) & 46.0 & 2001 & 57.3 & 2006 \\
\hline $\begin{array}{l}\text { Primary completion rate, female (percent of } \\
\text { relevant age group) }\end{array}$ & 51.0 & 2005 & 52.9 & 2006 \\
\hline
\end{tabular}

Source: World Bank, World Development Indicators online, retrieved January 9, 2009. 


\section{References}

Agha, S. 2000. "Is Low Income a Constraint to Contraceptive Use Among the Pakistani Poor?" Journal of Biosocial Science 32(2): 162-275.

Ahmed, T. N.d. "Review of Population Issue: Family Planning Policies and Programmes." Publisher unknown.

_. 2000a. "Pricing Reproductive Health Series in Pakistan.” Multi-donor Support Unit for Social Action Programme. Islamabad.

_. 2000b. "Situation Analysis of Social Marketing of Contraceptives in Pakistan." Multi-donor Support Unit for Social Action Programme. Islamabad.

\section{- 2002. Exploiting Social Marketing} Potentials for Fertility Reduction Goals in Pakistan. Multi-donor Support Unit for Social Action Programme.

Ahmed, F.A., A.M. Mohamed, and D. Khan. 1994. "An Aggregate Level Analysis of Fertility in Pakistan, 1990/91." CDC 24th Annual Seminar on Population Issues and the Challenges in the 21st Century in the Middle East, Africa, and Asia. Cairo Demographic Center, Cairo.

Ali, M. and H. Ushijima. 2005. "Perception of Men on Role of Religious Leaders in Reproductive Health Issues in Rural Pakistan." Journal of Biosocial Science 37: 115122.

Ali, S., S. Rozi, and M.A. Mahmood. 2004. "Prevalence and Factors Associated with Practice of Modern Contraceptive Methods among Currently Married Women in District Naushahro Feroze." Journal of Pakistan Medical Association 54(9): 461-65.

Ali, S., and F.M.M. White. 2005. "Family Planning Practices among Currently Married Women in Khairpur District, Sindh, Pakistan." Journal of College of Physicians and Surgeons Pakistan 15(7): 422-25.

Aziz, A. 1994. "Proximate Determinants of Fertility in Pakistan." Pakistan Development Review 33(4): 727-42.

Bongaart, J. 1978. "A Framework for Analyzing the Proximate Determinants of Fertility." Population and Development Review 4(1): 105-32.

Casterline, J., Z. Sathar, and M. ul Haque. 2001. "Obstacles to Contraceptive Use in Pakistan: A Study in Punjab." Studies in Family Planning 32 (2): 95-110.

Douthwaite, M., and P. Ward. 2005. "Increasing Contraceptive Use in Rural Pakistan: An Evaluation of the Lady Health Worker Programme." Health Policy and Planning 20(2): 117-23.

Federal Bureau of Statistics, Government of Pakistan. Various years. Pakistan Demographic Survey 2001, 2003, and 2005. Feeney, G., and I. Alam. 2003a. "Fertility, Population Growth, and Accuracy of Census Enumeration in Pakistan: 19611998.” In A.R. Kemal, M. Irfan, and 
N. Mahmood, eds., Population of Pakistan: An Analysis of 1998 Population and Housing Census. Islamabad: Pakistan Institute of Development Economics.

_ 2003b. "New Estimates and Projections of Population Growth in Pakistan." Population and Development Review 29(3): 483-492.

Greenstar Social Marketing Pakistan (Guarantee) Ltd. "Family Planning and Reproductive Health.” Retrieved February 29, 2009, from www.greenstar.org.pk/FPRH. htm.

Guttmacher Institute. 2009. "Abortion in Pakistan." In Brief. Series 2. www.guttmacher.org/pubs/IB_Abortion-in-Pakistan.pdf.

Hakim, A. 2001. "Population Policy Shifts and Their Implications for Population Stabilisation in Pakistan." Pakistan Development Review 40 (3): 551-70.

Hardee, K., and E. Leahy. 2008. "Population, Fertility and Family Planning in Pakistan: A Program in Stagnation." Research Commentary 3(1). Population Action International, USA. www.populationaction.org/ Publications/Working_Papers/Population_ Fertility_and_Family_Planning_in_Pakistan/Summary.shtml.

Hausmann, R., L.D. Tyson, and S. Zahidi. 2008. The Global Gender Gap Report 2007. Geneva: World Economic Forum.

Hussain, R., F.F. Fikree, H.W. Berendes. 2000. "The Role of Son Preference in Reproductive Behavior in Pakistan." Bulletin of the World Health Organization 78(3): 379-88.

Islam, A., F.A. Malik, and S. Basarja. 2002. "Strengthening Primary Health Care and Family Planning Services in Pakistan:
Some Critical Issues." Journal of Pakistan Medical Association 52(1) 2-7.

Jejeebhoy, S.J., and Z.A. Sathar. 2001. "Women's Autonomy in India and Pakistan: The Influence of Religion and Region." Population and Development Review 27(4): 687-712.

Kadir, M.M., F.F. Fikree, A. Khan, and F. Sajan. 2003. "Do Mothers-In-Law Matter? Family Dynamics and Fertility Decision-Making in Urban Squatter Settlements of Karachi, Pakistan." Journal of Biosocial Science 35(4): 545-58.

Karim, M.S., T. Ahmed, R. Ahmed, and Y.S. Qazi. 2004. "Family Planning in Pakistan: A Situation Analysis of Programs and Policies and Future Directions." In Z.A. Bhutta, ed., Maternal and Child Health in Pakistan: Challenges and Opportunities. New York: Oxford University Press USA. Karim M. S. 2005 "Islamic Teaching on Reproductive Health." in G. Jones and M. S. Karim (eds) Islam, the State and Populatio. London: Hearst \& Co.

Khan, A. 1999. "Mobility of Women and Access to Health and Family Planning Services in Pakistan." Reproductive Health Matters 7(14): 39-48.

Kiani, M.F.K. 2003. "Motivation and Involvement of Men in Family Planning in Pakistan." The Pakistan Development Review 42(3): 197-217.

King, E.M., and M.A. Hill. 1998. Women's Education in Developing Countries: Barriers, Benefits, and Policies. Washington, D.C.: World Bank.

Lee, K., L. Lush, G. Walt, and J. Cleland. 1998. "Family Planning Policies and Programmes in Eight Low-Income Countries: 
A Comparative Policy Analysis." Social Science and Medicine 47(7): 949-59.

Lush, L., G. P. Cernada, A. K. Ubaidur Rob, M. S. Arif, M. Ul Haque, and M. S. Ahmad. 1998. "Operations Research on the Female Village-Based Family Planning Worker Program of Pakistan." International Quarterly of Community Health Education 18(3): 283-305.

Lush, L., J. Cleland, K. Lee, and G. Walt. 2000. "Politics and Fertility: A New Approach to Population Policy Analysis." Population Research and Policy Review 19(1): 1-28.

Mahmood, N. 2002. "Women's Role in Domestic Decisionmaking in Pakistan: Implications for Reproductive Behaviour." The Pakistan Development Review 41: 2: 121-48.

Ministry of Population and Welfare. MoPW website http://www.mopw.gov.pk/.

Ministry of Population and Welfare., 2008., The Year Book 2007--08.

National Institute of Population Studies. 2007. Status of Women, Reproductive Health, and Family Planning Survey. Islamabad. 1998. 1998 Census. Islamabad.

National Institute of Population Research and Training, Mitra and Associates, and

Macro International Inc. 2005. 2004 Bangladesh Demographic and Health Survey. Dhaka.

Ministry of Health and Population, New ERA, and Macro International Inc. 2007. 2006 Nepal Demographic and Health Survey. Kathmandu.

International Institute for Population Sciences. 2007. 2005-06 India National Family and Health Survey (NFHS-3). New Delhi.
Department of Census and Statistics. 2008. 2006-07 Sri Lanka Demographic and Health Survey. Colombo.

National Institute of Public Health, National Institute of Statistics, ORC Macro. 2006. 2005 Cambodia Demographic and Health Survey. Phnom Penh.

National Institute of Population Studies and Macro International Inc. 1992. Pakistan Demographic and Health Survey 1990-91. Islamabad.

- 2008. Pakistan Demographic and Health Survey 2006-07. Islamabad.

Nishtar, S., M. Ahmad, S. Amjad, and S. Sheikh. 2008. "Synergizing Population and Health in Pakistan." Journal of the Pakistan Medical Association 59 (9): S3S23.

Organisation for Economic Co-operation and Development. OECD StatExtracts (Creditor Reporting System). Extracted March 26, 2009, from http://stats.oecd.org/WBOS/ Index. aspx? DatasetCode $=C R S N E W$.

Oxford Policy Management. 2002. "Lady Health Worker Programme: External Evaluation of the National Programme for Family Planning and Primary Care (Final Report)." Oxford, U.K.

Pakistan Federal Bureau of Statistics. 2003. 2001-02 Pakistan Integrated Household Survey (PIHS). Islamabad.

\section{-2006-07 Pakistan Social and Living} Standards Measurement Survey (PSLSMS). Islamabad.

- 2008. 2006-07 Labor Force Survey. Islamabad.

Popalzai, H., and J. Sikander. 2000. Evaluation of Village-Based Family Planning Workers Scheme in Pakistan. National Institute of Population Studies, Islamabad. 
Population Council. 1998. "Withdrawal in Pakistan: New Insight into an Old Method." Population Briefs 4(3):6.

Rehan, N. 2003. "Attitudes of Health Care Providers to Induced Abortion in Pakistan." Journal of the Pakistan Medical Association 53(7): 293-96.

Robinson, W.C. 2007. "Family Planning Programs and Policies in Bangladesh and Pakistan." In The Global Family Planning Revolution: Three Decades of Population Policies and Programs ed. W.C. Robinson and J.A. Ross. Washington, D.C.: World Bank. Saleem, S., and F.F. Fikree. 2005. "The Quest for Small Family Size among Pakistani Women-Is Voluntary Termination of Pregnancy a Matter of Choice or Necessity?" Journal of the Pakistan Medical Association 55(7): 288-91.

Saleem, S., and M.A. Isa. 2004. "Facilitating Inter-Spousal Communication for Birth Spacing-A Feasibility Study of Pakistan Couples for Policy Implications.” Journal of the Pakistan Medical Association. 54(4): 182-86.

Sathar, Z. 2007. "Stagnation in Fertility Levels in Pakistan." Asia-Pacific Population Journal 3 (3): 113-31.

Sathar, Z., and J. Casterline. 1998. "The Onset of Fertility Transition in Pakistan." Population and Demographic Review 24(4): 773-96.

Sathar, Z., and S. Kazi. 2000. "Women's Autonomy in the Context of Rural Pakistan." The Pakistan Development Review 39(2): 89-110.

Sathar, Z., C.B. Lloyd, C. Mete, and M. ul Haque. 2000. "Schooling Opportunities for Girls as a Stimulus for Fertility Change in Rural.” Policy Research Di- vision Working Paper 143. Population Council, New York.

Sathar, Z., S. Singh, and F.F. Fikree. 2007. "Estimating the Incidence of Abortion in Pakistan." Studies in Family Planning 38(1): 11-22.

Soomro, G.Y., and N. Mahmood. 2005. "Female Education and Fertility: Implications for Family Planning Programme." Pakistan Society of Development Economists papers presented in 20th Annual General Meeting. Pakistan Institute of Development Economics, Islamabad.

Stephenson, R., and M. Hennink. 2004. "Barriers to Family Planning Service Use among the Urban Poor in Pakistan.” Opportunities and Choices Working Paper

2. University of Southampton, Southampton, U.K.

Sultan, M., J.G. Cleland, and M.M. Ali. 2002. "Assessment of a New Approach to Family Planning Services in Rural Pakistan." American Journal of Public Health 92(7): 1168-72.

Winkvist, A., and H.Z. Akhtar. 2000. "God Should Give Daughters to Rich Families Only: Attitudes Towards Childbearing among Low-Income Women in Punjab, Pakistan." Social Science \& Medicine 51(1): 73-81.

World Bank. 1990. "Project Completion Report for the Population Project." Report No. 9262. December. Washington, D.C. __ 1998. "Implementation Completion Report for Social Action Program Project.” Report No. 18043. June. Washington, D.C.

__ 2000a. "Implementation Completion Report for the Family Health I Project." Report No. 21497. Washington, D.C. 
. 2000b. "Implementation Completion Report for the Family Health II Project.” Report No. 20602. Washington, D.C.

2000c. "Implementation Completion Report for the Population Welfare Program Project.” Report No. 20614. Washington, D.C.

_. 2001. "Implementation Completion Report for the Northern Health Program Project.” Report No. 22263. Washington, D.C. 2002. "Pakistan Country Assistance Strategy." Washington, D.C. 2003. "Implementation Completion Report for Second Social Action Program
Project." Report No. 26216. Washington, D.C.

2005. Pakistan: Country Gender Assessment_Bridging the Gender Gap: Opportunities and Challenges. Washington, D.C.

2006. World Development Indicators 2006. Washington, D.C.

. 2007. World Development Indicators 2007. Washington, D.C.

Zafar, MI., F. Asif, and S. Adil. 2003. "Religiosity as a Factor of Fertility and Contraceptive Behavior in Pakistan." Pakistan Journal of Applied Sciences 3(3): 158166. 


\section{Endnotes}

$1 \quad$ Population projection based on 1998

Census prepared by National Institute of Population Studies (2005).

2 Feeney and Alam 2003a.

3 Sathar and Casterline 1998.

4 Feeney and Alam (2003b) question whether the total fertility rate really fell that rapidly or whether the rate of decline was exaggerated by the deterioration in the quality of birth reporting. However, agreement among several independent estimates suggests that the estimates are all at least approximately correct.

5 The total fertility rate calculated from the Pakistan Demographic Survey, a large sample survey conducted by the Federal Bureau of Statistics, is based on births reported during the past year. The total fertility rate calculated from the surveys conducted by the Ministry of Population Welfare and the National Institute of Population Studies is based on three- to fiveyear recall of births, which are likely to be underreported by uneducated women.

6 Feeney and Alam 2003a. Sathar and Casterline (1998) also argue that 1990-91 Pakistan Demographic and Health Survey fertility rate was seriously underestimated.

7 Feeney and Alam 2003b.

8 Sathar 2007.

9 These were suggested Bongaart (1978).

10 Aziz 1994 and Ahmed, Mohamed, and Khan 1994.
11 Sathar and Casterline 1998; Sathar 2007.

12 Sathar 2007.

13 A measure comparing the age-specific proportions of women who have never been married with the age-specific proportions of those who have ever been married to calculate the mean age at which the transition between the two occurs. It is used to estimate mean age at marriage in countries where marriage records are absent or deficient.

14 Pakistan Demographic and Health Survey data (National Institute of Population Studies and Macro International Inc. 1992, 2008).

15 Pakistan Demographic and Health Survey data (National Institute of Population Studies and Macro International Inc. 1992, 2008).

16 National Family Health Survey-III 2005-06 for India, Demographic and Health Survey 2006 for Nepal, Demographic and Health Survey 2004 for Bangladesh, and Demographic and Health Survey 2006-07 for Sri Lanka.

17 Sathar and Casterline 1998.

18 Pakistan Demographic and Health Survey 2006-07 (National Institute of Population Studies and Macro International Inc. 2008).

19 Pakistan Demographic and Health Surveys (National Institute of Population Studies and Macro International Inc. 1992, 2008).

20 Pakistan Demographic and Health Survey data (National Institute of Population 
Studies and Macro International Inc. 1992, 2008).

21 According to the 2006-07 Pakistan Demographic and Health Survey, about 60 percent of female sterilization clients reported that it was free of cost, compared with 30 percent of oral contraceptive users, 15 percent of intrauterine device users, 14 percent of condom users, and 13 percent of injectable contraceptive users (National Institute of Population Studies and Macro International Inc. 1992, 2008).

22 Pakistan Demographic and Health Survey 2006-07 (National Institute of Population Studies and Macro International Inc. 2008).

23 Pakistan Demographic and Health Survey 2006-07 (National Institute of Population Studies and Macro International Inc. 2008).

24 For Nepal, Demographic and Health Survey 2006; for Cambodia, Demographic and Health Survey 2005.

25 India National Family Health Survey III 2005-06.

26 Pakistan Demographic and Health Survey 2006-07 (National Institute of Population Studies and Macro International Inc. 2008).

27 Pakistan Demographic and Health Survey 2006-07 (National Institute of Population Studies and Macro International Inc. 2008).

28 Sathar, Singh, and Fikree 2007. This study used data from a health facilities survey covering 17 percent of public health facilities and 65 percent of hospital beds in public facilities, and a health professionals survey conducted in 2002, which used structured interviews of 154 health professionals across the country. Both ques-

tionnaires were adopted from instruments developed by the Guttmacher Institute.$$
200
$$
tion Studies and Macro International Inc. 2008).

34 Pakistan Demographic and Health Survey 1990-91 and 2006-07 (National Institute of Population Studies and Macro International Inc. 1992, 2008).

35 Iram and Butt 2008, using data from Pakistan Integrated Household Survey 2001-02.

36 (National Institute of Population Studies and Macro International Inc. 1992, 2008) Survey 1990-91 and 2006-07.

37 Pakistan Demographic and Health Survey 1990-91 and 2006-07 (National Institute of Population Studies and Macro International Inc. 1992, 2008).

38 Pakistan Demographic and Health Survey 2006-07 (National Institute of Population Studies and Macro International Inc. 2008).

39 Winkvist and Akhtar 2000. Pakistan Gender Assessment 2005, based on Pakistan Integrated Household Survey 2001-02.

45 Pakistan Demographic and Health Survey 1990-91 and 2006-07 (National Institute of Population Studies and Macro International Inc. 1992, 2008). 
47 The Pakistan Gender Assessment 2005. Federal Bureau of Statistics 2008).

51 Conventionally, people ages 10 and older reporting housekeeping and related activities are considered out of the labor force. However, from the perspective of time use, they are identified as employed if they have spent time on a specific set of marginal economic activities (Labor Force Survey 2006-07, table 6, Pakistan Federal Bureau of Statistics 2008).

52 Pakistan Demographic and Health Survey 2006-07 (National Institute of Population Studies and Macro International Inc. 2008). phenson and Hennink 2004; Ali and White 2005.

61 Ali, Rozi, and Mahmood 2004.

62 2006-07 (National Institute of Population Studies and Macro International Inc. 2008).

69 The increase in the price of condoms in 1991 might have contributed to the increased use of withdrawal after 1991 (Agha 2000).

70 Population Briefs 1998.

71 Ahmed n.d.

72 Karim and others 2004.

73 Ahmed n.d; Hakim 2001; Lush and others 2000; Lee and others 1998.

74 UNFPA 1998.

75 Nishtar and others 2008.

76 Ministry of Population and Welfare 2008.

77 According to the Ministry of Health website, there are 13,937 health facilities. Of those, 371 Tuberculosis Centers and 1,080 First Aid Points do not offer contraceptives.

78 Robinson 2007.

79 Karim and others 2004.

80 Karim and others 2004.

81 Pakistan Integrated Household Survey 2001-02 (Pakistan Federal Bureau of Statistics 2003).

82 Pakistan Demographic and Health Survey 2006-07 (National Institute of Population Studies and Macro International Inc. 2008); disaggregated data on the source of modern contraceptives by residence (rural and urban areas) are not available.

83 Pakistan 2006-07 Social and Living Standards Measurement Survey (Pakistan Federal Bureau of Statistics 2008).

84 The evaluation study was conducted during 1998-99 by the National Institute of Pakistan Studies with a random sample of 73 family welfare centers ( 5 percent of the total) and 80 clients from each family welfare center contacted.

85 Pakistan Integrated Household Survey 2001-02 (Pakistan Federal Bureau of Statistics 2003). 
86 Pakistan Demographic and Health Survey 2006-07 (National Institute of Population Studies and Macro International Inc. 2008).

87 Sultan, Cleland, and Ali 2002.

88 Agha 2000.

89 Ahmed 2000a.

90 The evaluation (Popalzai and Sikander 2000) covered the performance of villagebased family planning workers, verification of clients and their views, and the role of trainers and supervisors. Systematic random sampling was used to select 373 family planning workers out of 7,446. As a second stage, 15 eligible women per worker were selected for interviews, along with 145 trainers and supervisors.

91 Lush and others 1998 and Sultan; Cleland, and Ali 2002. The evaluation by Lush and others involved three community surveys (August and December 1993 and No- vember 1994) of 10 percent of households in 21 villages (about 400 interviewees per survey) and a series of observation studies in Punjab for 550 observations of interactions with clients and 76 workers were collected.

92 A logistic regression analysis by Douthwaite and Ward (2005) using data collected for the program evaluation conducted in 1999-2002 by Oxford Policy Management (sample survey of 4,277 women living in households served by the LHWP or in control areas).

93 Islam, Malik, and Basarja 2002.

94 Greenstar Social Marketing website at http://www.greenstar.org.pk/FPRH.htm

95 Pakistan Demographic and Health Survey 2006-07 (National Institute of Population Studies and Macro International Inc. 2008).

96 Ahmed 2002.

97 Ahmed 2002.

98 Oxford Policy Management 2002. 
1818 H Street, N.W.
Whashington, DC 2043

1818 H Street, N.W.
Whashington, DC 2043

THE WORLD BANK
Washington, DC 20433

(2)

(1)

更

(1)

(2)

\author{
Washington, DC 20433
}

3

